\title{
Deformación andina en el cordón del Hielo Azul al oeste de El Bolsón. Implicancias en la evolución tectónica de la Cordillera Norpatagónica en Río Negro, Argentina
}

\author{
Jonathan E. Tobal ${ }^{1}$, Emilio Rojas Vera ${ }^{1}$, Andrés Folguera ${ }^{1}$, Víctor A. Ramos ${ }^{1}$
}

${ }^{1}$ Laboratorio de Tectónica Andina del Instituto de Estudios Andinos Don Pablo Groeber, Universidad de Buenos Aires-CONICET, Ciudad Universitaria, 1428, Buenos Aires, Argentina.

jonathantobal@gmail.com; rv081@yahoo.com.ar; andresfolguera2@yahoo.com.ar; andes@gl.fcen.uba.ar

\begin{abstract}
RESUMEN. Estudios geológicos de campo realizados en el cordón del Hielo Azul, al oeste de la localidad de El Bolsón, a los $42^{\circ} \mathrm{S}$ en la Cordillera Norpatagónica (provincia de Río Negro, Argentina), permitieron establecer las distintas relaciones de contacto existentes entre las rocas volcanosedimentarias cordilleranas del Jurásico Inferior, las plutonitas del Batolito Patagónico Cordillerano del Jurásico Medio Superior y las volcanitas cenozoicas de la Formación Ventana. El análisis estructural de las unidades aflorantes mencionadas permitió identificar varias estructuras de deformación previamente desconocidas en este sector de los Andes. Se observó que las rocas volcánicas jurásicas que afloran en el cerro Lindo, al oeste de El Bolsón, se encuentran limitadas por un retrocorrimiento al este y un corrimiento fuera de secuencia al oeste; además se hallan afectadas por dos corrimientos, a los que se asocian estructuras plegadas de menor orden. Al norte, en el cerro Hielo Azul, se observó que las volcanitas jurásicas en su sector occidental se encuentran en contacto tectónico con las volcanitas de la Formación Ventana. Las observaciones de campo permiten inferir la existencia de una falla extensional que controló la depositación de las volcanitas cenozoicas, la cual habría sido luego invertida, sobreponiendo estas rocas a las volcanitas jurásicas. Las distintas fallas reconocidas ejercieron un control de primer orden en el proceso de estructuración del frente montañoso y son, por lo tanto, importantes para comprender el marco tectónico y el levantamiento de la Cordillera Norpatagónica. Se interpreta que la deformación tuvo lugar entre en el Eoceno y el Mioceno Tardío. Un pulso contraccional preoligoceno dio lugar al desarrollo de una faja plegada y corrida de piel fina que afectó a las volcanitas jurásicas. Durante el Oligoceno tuvo lugar un evento extensional de escala regional que dio lugar a la formación de depocentros como el que se reconoce en el cerro Silvia, donde aflora la Formación Ventana. Un segundo pulso contraccional desarrollado durante el Mioceno originó una faja plegada y corrida a través de fallas de basamento que levantaron el frente montañoso actual.
\end{abstract}




\begin{abstract}
Andean deformation at the Cordón del Hielo Azul, El Bolsón, Río Negro (Argentina). Implications for the tectonic evolution of the North Patagonian Andes. This geological study, carried out in the Cordón del Hielo Azul, west of the El Bolsón town (Río Negro province, Argentina), shows the different relationships between the Early Jurassic cordilleran volcanosedimentary sequence, the Middle-Upper Jurassic Cordilleran Patagonian Batholith and the Cenozoic volcanic rocks of the Ventana Formation exposed in the Patagonian Cordillera of Río Negro. Through structural analysis, a series of previously unknown complex deformational structures have been identified. It has been observed that the sequence of volcanic rocks that outcrop on the Cerro Lindo, just west of El Bolsón, is bounded by a backthrust in the eastern side and by an out of sequence thrust to the west; two other thrusts affect the sequence, with associated folded structures. To the north, on the west side of Cerro Hielo Azul, these Lower Jurassic volcanic rocks are in tectonic contact with the Cenozoic rocks of the Ventana Formation. Based on these observations, we inferred that an extensional fault controlled deposition of the Cenozoic volcanic rocks, being subsequently inverted, superimposing these rocks on the Jurassic volcanics. The different recognized faults exerted a first order control in the building of the mountain front and are robust evidence to establish the tectonic framework and uplift history of the North Patagonian Andes. This deformation took place from the Eocene to the Late Miocene. A pre-Oligocene contractional pulse led to the development of a thin-skinned fold and thrust belt affecting the Jurassic volcanics. During the Oligocene a regional extensional event resulted in the formation of basins such as the one recognized on Cerro Silvia, where the Ventana Formation crops out. A second contractional pulse took place during the Miocene and led to the development of a thick-skinned fold and thrust belt with deep faults that built the present mountain front.
\end{abstract}

Keywords: North Patagonian Andes, Structure, Andean Tectonics, Fold and thrust belt, Argentina.

\section{Introducción}

El grado de conocimiento de la estructura andina resulta dispar. Sectores considerables de los Andes Patagónicos se encuentran parcialmente descritos o permanecen inexplorados; las dificultades de acceso a numerosas áreas cordilleranas, por la combinación de una densa cobertura vegetal y un relieve abrupto, explican esta escasez de datos de campo. Así, las distintas estructuras que exhuman las secuencias aflorantes en este sector de los Andes no han sido completamente identificadas.

En particular, la falta de información estructural del sector cordillerano más occidental de la Cordillera Norpatagónica no ha permitido hasta aquí determinar con claridad las principales fases de construcción andina y por lo tanto la evolución tectónica. Así resulta que, aunque existe una considerable cantidad de información termocronológica -principalmente en territorio chileno- (Thomson, 2002; Thomson et al., 2001; Adriasola et al., 2006; Glodny et al., 2007), los pulsos de exhumación determinados por trazas de fisión solo pueden ser asociados a fases orogénicas conceptuales ante la falta de conocimiento de la estructura regional.

La zona de estudio de este trabajo comprende el sector cordillerano ubicado al oeste de El Bolsón, localidad argentina situada sobre el valle de El Bolsón, a 300 m s.n.m, 8 km al norte del paralelo de $42^{\circ} \mathrm{S}$ que define el límite entre las provincias de
Río Negro y Chubut, sobre la vertiente argentina de los Andes.

El presente trabajo describe en detalle los corrimientos que han formado la vertiente oriental de la Cordillera Patagónica a los $42^{\circ} \mathrm{S}$, agrupándolos temporalmente, con el objeto de presentar una cronología de deformación que tenga aplicabilidad para el conjunto de la Cordillera Norpatagónica. Adicionalmente, se trata de demostrar que durante las fases contraccionales que condujeron a la formación de la faja plegada y corrida andina, se intercalaron fases extensionales.

El valle de El Bolsón, que constituye el límite oriental de la zona de estudio, tiene un rumbo nortesur y se encuentra circunscrito por los cordones del Piltriquitrón y del Hielo Azul, que se elevan al este y al oeste respectivamente (Fig. 1). El cordón del Hielo Azul comprende el cerro homónimo y el cerro Lindo, así como los cerros Silvia y Alicia, que conforman una segunda línea de cumbres al oeste, junto a una serie de filos montañosos prácticamente inaccesibles (Fig. 2). Los datos de campo que se presentan en este estudio corresponden a este sector montañoso.

En términos regionales, el cordón del Hielo Azul se inscribe dentro del segmento de los Andes Patagónicos Septentrionales, los cuales se extienden a lo largo de más de $500 \mathrm{~km}$, entre los 39 y $45^{\circ} \mathrm{S}$. Algunos de los rasgos más salientes de la Cordillera Patagónica a estas latitudes son un frente montañoso abrupto, laderas cubiertas por la vegetación por 


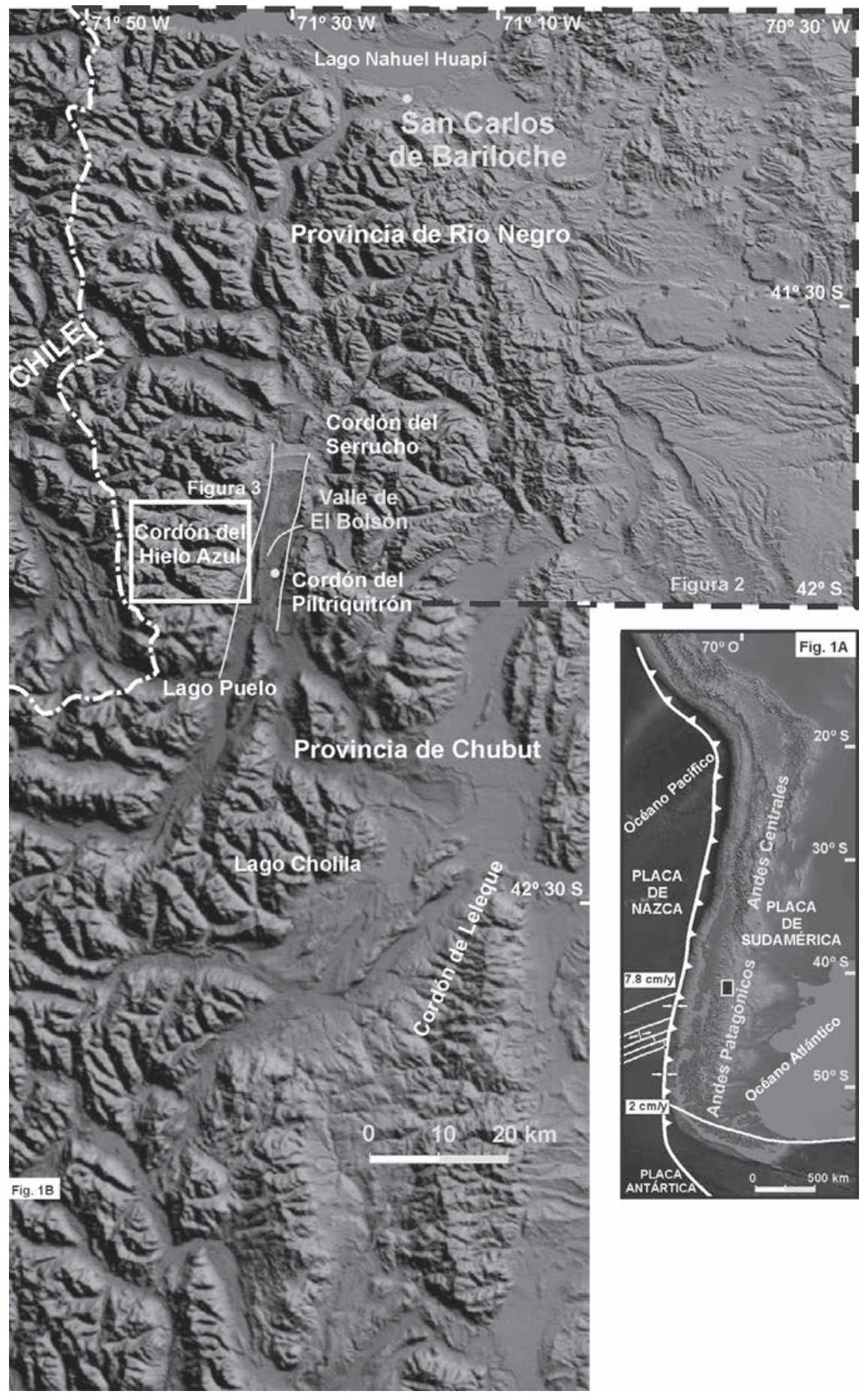

FIG. 1. A. Ubicación del área de estudio a escala continental; B. Modelo de elevación digital de la región estudiada (vertiente oriental de los Andes Patagónicos Septentrionales entre los $41^{\circ}$ y los $42^{\circ}$ S) (ASTER GDEM tomado de http://www.gdem.aster.ersdac.or.jp). Se ha incluido la toponimia más relevante y se encuentran identificados los principales rasgos topográficos: obsérvese el valle de El Bolsón en que se sitúa la localidad homónima, el cual constituye un rasgo lineal NNE de primer orden que separa la Cordillera Patagónica al oeste de los relieves precordilleranos al este. El recuadro en blanco delimita el área de estudio de este trabajo, correspondiente al cordón del Hielo Azul. El recuadro en línea punteada corresponde a la figura 2. 


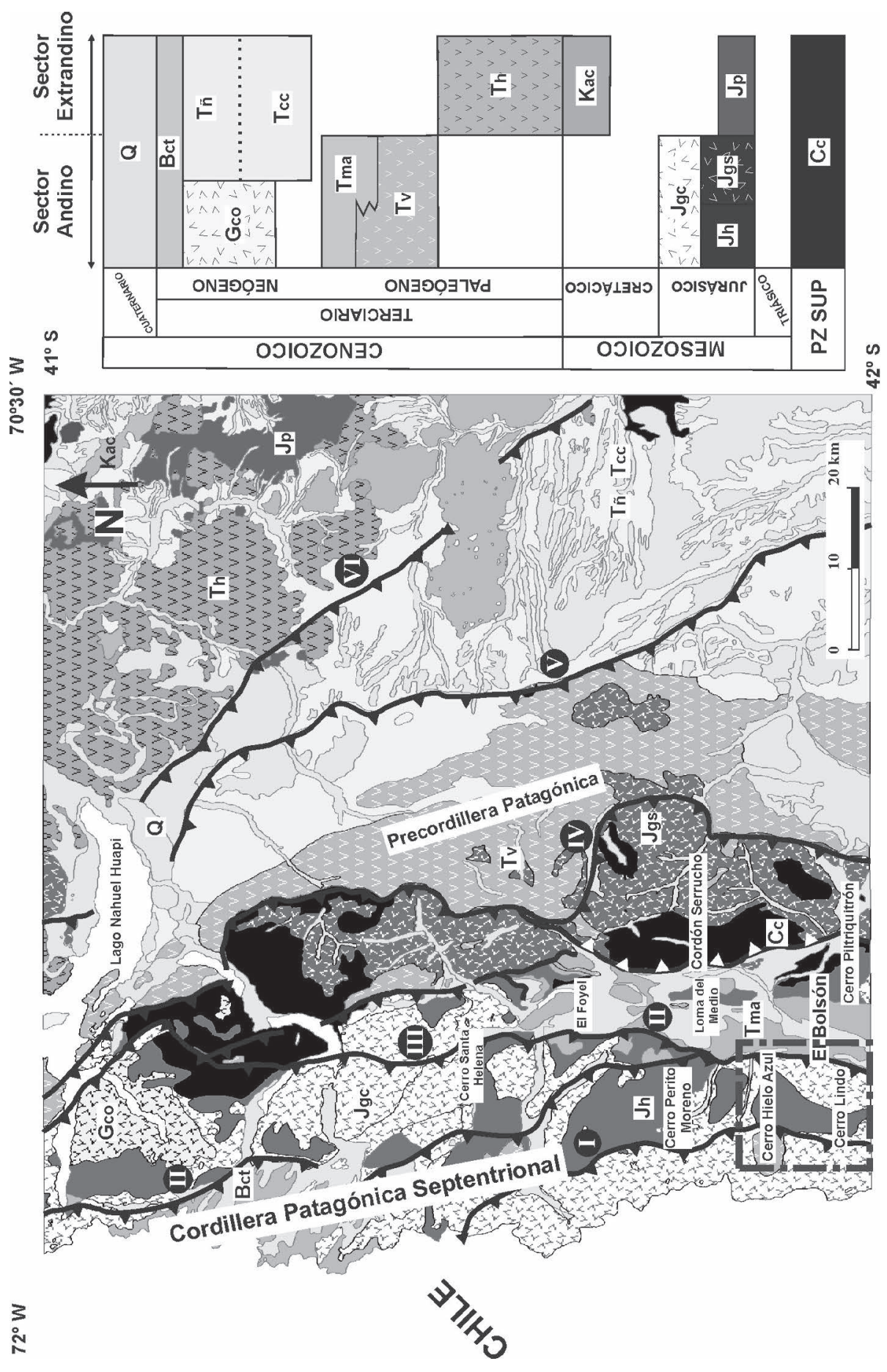


debajo de los $1700 \mathrm{~m}$ aproximadamente y cumbres que no superan los 2500 m s.n.m, con la excepción del cerro Tronador, un edificio volcánico cuaternario que alcanza los $3478 \mathrm{~m}$.

La falta de conocimiento geológico del sector contrasta con la de los sectores precordilleranos al este. En estos sectores, los trabajos de Ramos (1981)1, Ramos y Cortés (1984), y los de Giacosa y Heredia $(1999,2004)$ constituyen los antecedentes más relevantes, al haber reconocido, descrito e interpretado la faja plegada y corrida desarrollada al este de la Cordillera Patagónica de Río Negro, con pocas -y muy acotadas- referencias respecto de las estructuras más occidentales.

Algunos trabajos pioneros han contribuido a la geología del área, incluyendo datos radiométricos y hallazgos fosilíferos (González Bonorino, 1974; González Bonorino y González Bonorino, 1978; Thiele et al., 1978; González Díaz, 1982; González Díaz y Lizuaín, 1984; Lizuaín, 1980, 1981, 1999). El trabajo más detallado que cubre la zona de estudio es el de Diez y Zubia (1981). En territorio chileno, el mapeo geológico ha sido bosquejado por Thiele et al. (1978) y Duhart et al. (2000).

\section{Estratigrafía}

La geología de la zona andina y extrandina entre los $41^{\circ}$ y los $42^{\circ} \mathrm{S}$ consta de: i) una unidad de basamento del Paleozoico superior, el Complejo Colohuincul; ii) unidades mesozoicas que incluyen una secuencia volcanosedimentaria y los batolitos patagónicos cordillerano y subcordillerano; iii) unidades cenozoicas, con predominio de volcanitas de las formaciones Ventana y Huitrera, y sedimentitas de las formaciones Collón Cura y Ñirihuau.

Según puede verse en la figura 2, existe una relación entre la disposición de las distintas unidades aflorantes y las estructuras que definen la faja plegada y corrida a estas latitudes, tema que se desarrollará en detalle en la sección 3.

A grandes rasgos, el Complejo Colohuincul y las unidades mesozoicas se disponen al oeste del corrimiento Ventana-Catedral. Al este de dicha estructura afloran las volcanitas paleógenas de las formaciones Ventana y Huitrera, distribuidas a lo largo dos fajas volcánicas, una interna al oeste y una externa al este, respectivamente, y las sedimentitas neógenas de las formaciones Collón Cura y Ñirihuau, que forman el relleno de la cuenca de Ñirihuau.
A continuación, se describen en detalle las cuatro unidades aflorantes en el área de estudio y el basamento, que aunque no aflora estrictamente en el cordón del Hielo Azul, sí lo hace inmediatamente al este, en los cordones Serrucho y Piltriquitrón (Fig. 3). Además, se hace mención a unidades geológicas que no afloran en el área de estudio que se encuentran temporal, espacial o genéticamente vinculadas con estas cuatro unidades para una mejor comprensión de sus relaciones.

\subsection{Basamento metamórfico (Paleozoico superior)}

Aunque no aflora estrictamente en el área de estudio, el Complejo Colohuincul constituye el basamento de gran parte de la región cordillerana de Río Negro (Fig. 2; Giacosa et al., 2001). El nombre fue acuñado por Turner (1965), quien denominó Formación Colohuincul a las metamorfitas de la zona cordillerana de Aluminé. Dalla Salda et al. (1991) y Giacosa et al. (2001) describen esta unidad ígneo-metamórfica con el nombre de Complejo Colohuincul.

La unidad se dispone en contacto tectónico con la Formación Ventana al este del lago Gutiérrez (García Sansegundo et al., 2009) y más al sur, en el cordón Serrucho, con las sedimentitas del valle de El Bolsón (Giacosa et al., 2001). En el faldeo oriental del cordón Piltriquitrón, inmediatamente al este del área de estudio, rocas del denominado complejo volcanosedimentario de edad mesozoica se asientan en discordancia angular sobre esta unidad (Giacosa et al., 2001).

En términos generales, el Complejo Colohuincul está integrado por metamorfitas de grado medio a alto, variando de sur a norte entre gneises anfibólicos poco foliados, acompañados por anfibolitas de grano fino y micacitas gnéisicas, y esquistos micáceos y esquistos cuarzo-micáceos con venas de cuarzo y pegmatitas foliadas. En el cordón Piltriquitrón, se distinguen al norte ortogneises anfibólicos bien foliados con xenolitos aplanados; hacia el sur gradan a anfibolitas de grano fino, esquistos anfibólicos y sectores con ortogneises graníticos y esquistos cuarzo biotíticos (Giacosa et al., 2001).

Dos edades U-Pb SHRIMP de 323 y 330 Ma en el cordón Serrucho, en circones separados de una granodiorita, y una de 329 Ma ubicada a unos $50 \mathrm{~km}$ hacia el SE, en Río Chico en circones correspondientes a una tonalita, fueron reportadas por Pankhurst et al. (2006); éstas resultan compatibles con una edad

${ }^{1}$ Ramos, V.A. 1981. Evaluación fotogeológica Área Ñirihuau (inédito). Pluspetrol: 94 p. Buenos Aires. 


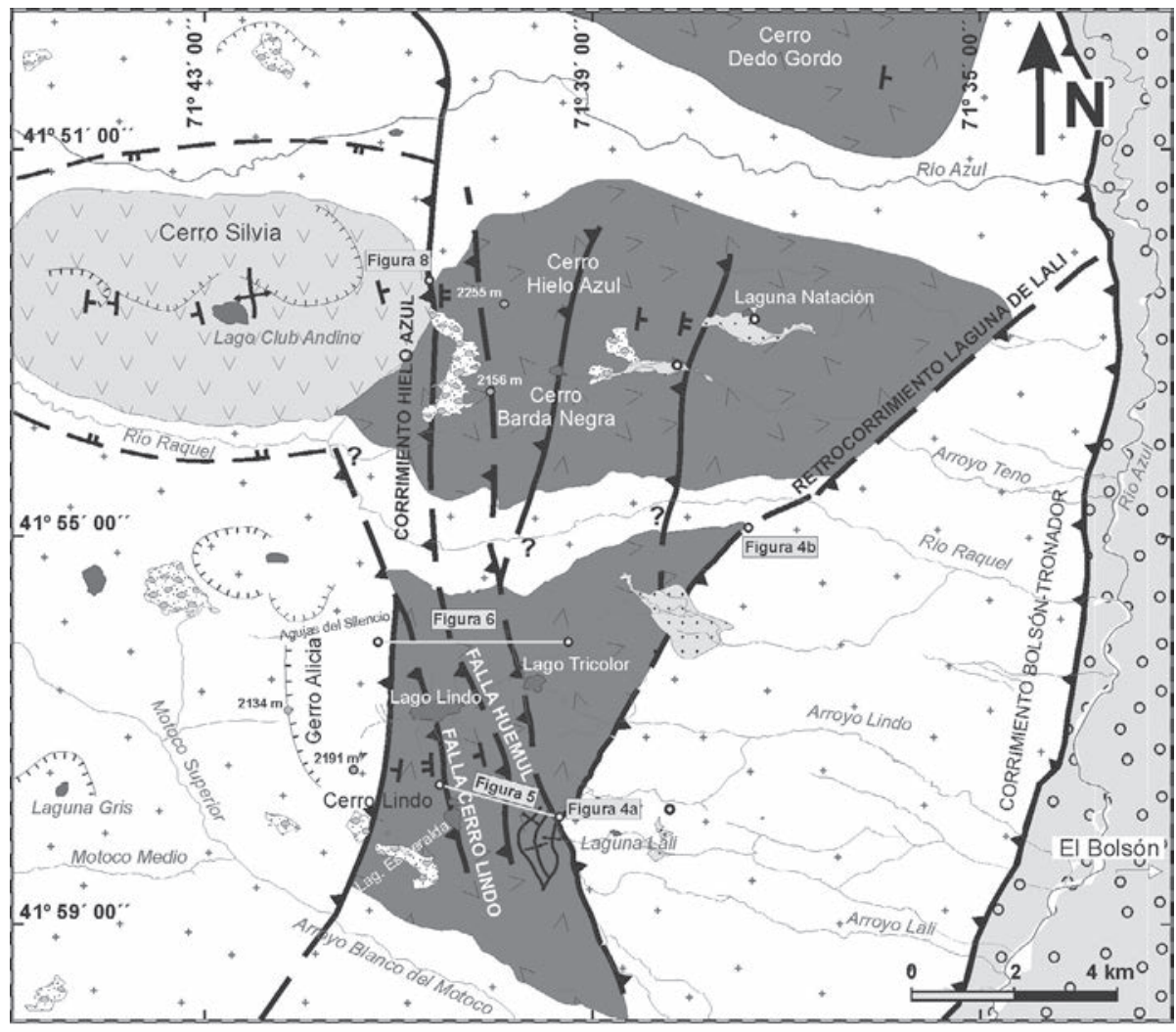

\section{COLUMNA ESTRATIGRÁFICA}

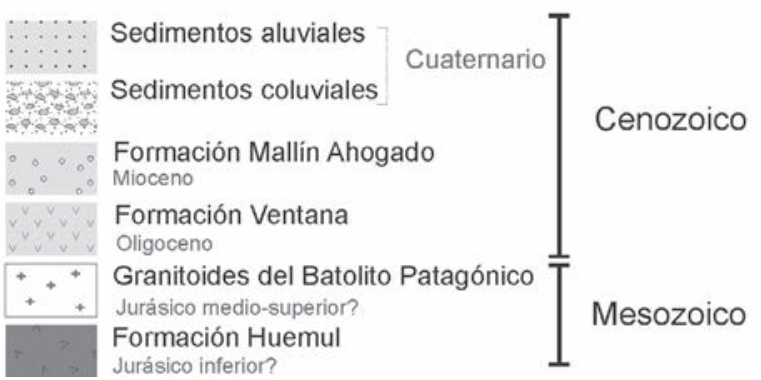

SIMBOLOGÍA

\begin{tabular}{|c|c|}
\hline 1 & Corrimiento \\
\hline 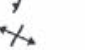 & Anticlinal \\
\hline & Sinclinal \\
\hline$y$ & Falla norma \\
\hline $0^{2255 \mathrm{~m}}$ & Cumbre \\
\hline$\circ$ & Refugio \\
\hline$q$ & Río \\
\hline 3 & $\begin{array}{l}\text { Circo glaciar } \\
\text { Lago }\end{array}$ \\
\hline
\end{tabular}

FIG. 3. Mapa geológico-estructural del cordón del Hielo Azul. Nótense dos corrimientos con vergencia opuesta que montan el Batolito Patagónico Cordillerano por sobre la Formación Huemul y definen una faja de deformación interpretada como una faja epidérmica. Una descripción detallada de las estructuras consta en la sección 3 del presente trabajo.

U-Pb de 320,7 $\pm 2,1$ Ma en una anfibolita que aflora en el Cañadón de la Mosca, obtenida por Varela et al. (2005). Se trata de edades de cristalización de las rocas.

García Sansegundo et al. (2009) han identificado tres eventos de deformación (D1, D2 y D3), desarrollados bajo condiciones de metamorfismo dispares y que afectaron a estas rocas del basamento.
Los autores asocian el evento D1 con el episodio de subducción desarrollado durante el Carbonífero temprano, relacionado con los granitoides de tipo-I estudiados por Pankhurst et al. (2006); los eventos de deformación D2 y D3 se habrían desarrollado entre el Carbonífero tardío y el Pérmico temprano, en relación con granitoides de tipo-S sintectónicos a postectónicos. 


\subsection{Formación Huemul (Jurásico Inferior)}

Estratigráficamente por encima del Complejo Colohuincul se dispone la Formación Huemul. Esta unidad consta de rocas volcánicas que forman parte de una secuencia volcanosedimentaria jurásica de extensión regional -afectada por intrusiones graníticas- reconocida por Quensel (1911) y Ljungner (1931) ya desde principios de siglo pasado. Tanto la ausencia de datos radiométricos precisos y de perfiles tipo, como la indeterminación respecto de la relación entre las facies sedimentarias y volcánicas, no han permitido hasta la actualidad caracterizar con precisión esta secuencia. La nomenclatura de esta unidad ha atravesado así una serie de controversias desde el trabajo de González Bonorino (1974), que exceden el objetivo de este trabajo. Para un resumen de los distintos criterios esgrimidos véase Lizuaín (1980, 1999) y Tobal (2010).

Debido a que las rocas reconocidas en los cerros Lindo y Hielo Azul se corresponden con las rocas descritas por González Bonorino (1974) y por Diez y Zubia (1981), tanto por su litología como por su distribución y disposición respecto de los granitoides cordilleranos, se prefiere aquí mantener el nombre Formación Huemul (sensu González Bonorino, 1974) para las mismas, evitando la vaguedad que introduce el uso del término complejo volcanosedimentario (sensu Giacosa et al., 2001).

Diez y Zubia (1981) caracterizaron la disposición de las rocas en la zona cordillerana como 'enclaves ('roof-pendants') en las partes superiores de los cuerpos graníticos cretácicos’ (Diez y Zubia, 1981; p. 22). Aunque el término resulta útil para describir la secuencia a nivel regional, las observaciones de campo realizadas en este estudio tornan la descripción insuficiente. En el estudio realizado en el cerro Lindo, se ha reconocido que las rocas volcánicas jurásicas se encuentran en contacto tectónico con las plutonitas del Batolito Patagónico Cordillerano, tanto al este como al oeste. Al norte, a la latitud del cerro Hielo Azul, la traza del corrimiento más occidental sobrepone rocas volcánicas cenozoicas por sobre la Formación Huemul. Relaciones de intrusividad por parte de las rocas plutónicas del Batolito Patagónico Cordillerano se observan en el cordón del Piltriquitrón y son frecuentes a escala regional (Giacosa et al., 2001); en el sector NE de dicho cerro, la Formación Huemul se asienta en discordancia sobre el Complejo Colohuincul.
En el área de estudio, las rocas afloran todo a lo largo del cordón del Hielo Azul, como una franja continua de rumbo norte-sur (Figs. 2 y 3). La secuencia jurásica analizada comprende únicamente la parte lávico-piroclástica de la sucesión volcanosedimentaria, predominando los tipos composicionales riodacíticos y andesíticos entre las lavas, con piroclastitas que coronan el tope expuesto de la sección, tal como fueran descritas por Diez y Zubia (1981). Las rocas presentan evidencias de deformación e intensa erosión glaciaria.

La edad de las rocas de la Formación Huemul es aún imprecisa. Giacosa et al. (2001) sugirieron una edad mínima de 130 \pm 10 Ma para los granitoides que intruyen las volcanitas en el cerro Piltriquitrón. Edades K-Ar en roca total que oscilan entre 120 y 155 Ma fueron presentadas por González Díaz (1982), mientras que fósiles hallados en el cerro Piltriquitrón y en la sierra Chata fueron asignados al Liásico (Lizuaín, 1980). El reciente trabajo de Castro et al. (2011), con edades U-Pb (SHRIMP) que sitúan los granitoides del Batolito Patagónico Cordillerano del área del río Manso inferior en el lapso Jurásico Medio-Tardío (149-170 Ma), establece una edad mínima de la secuencia de $170 \mathrm{Ma}$, corroborando la edad propuesta por Lizuaín (1980), quien las había asignado al Jurásico Inferior.

La depositación de las rocas habría tenido lugar en un ambiente extensional, en cuencas tipo 'graben' limitadas al este por umbrales 'horst' de basamento, donde se emplazaron las rocas plutónicas del Batolito Patagónico Subcordillerano (Giacosa y Heredia, 1999; Giacosa et al., 2001). Gabaldón y Lizuaín (1982) estudiaron en el cordón Piltriquitrón sedimentitas equivalentes a las facies sedimentarias de la Formación Huemul, para las que interpretaron un ambiente de sedimentación correspondiente a una llanura mareal en el tramo inferior de la sección, que bruscamente pasa a un ambiente de sedimentación dominado por canales submareales en el tramo superior de la sección, probablemente distributarios de un sistema deltaico. El estudio de las paleodirecciones de corriente indicaría aporte desde el oeste, por lo que el sector considerado habría constituido un borde de cuenca.

\subsection{Granitoides del Batolito Patagónico (Jurásico Medio a Superior)}

Se describen a continuación los batolitos patagónicos cordillerano y subcordillerano (Gordon y Ort, 1993). 
El Batolito Patagónico Subcordillerano está constituido por una serie de cuerpos plutónicos zonados, dominados por granodioritas hornblendo-biotíticas y monzodioritas cuarzosas de tipo-I, monzogranitos dioríticos y en menor medida por dioritas y leucogranitos que conforman un cinturón discontinuo (Spikermann et al., 1988, 1989; Gordon y Ort, 1993; Busteros et al., 1993; Haller et al., 1999). Estas plutonitas intruyen las rocas pertenecientes al Complejo Colohuincul y afloran fuera del área de estudio, al este de los cordones del Piltriquitrón y del Serrucho (Fig. 2). El desarrollo de los cuerpos plutónicos al oeste se encuentra limitado por el corrimiento López (Fig. 2), que ha sido interpretado como una paleoestructura que controló el desarrollo de la extensión jurásica, delimitando un alto de basamento en el que se emplazaron los plutones del Batolito Patagónico Subcordillerano (Giacosa et al., 2001). Edades U-Pb SHRIMP en circones, presentadas por Rapela et al. (2005), sitúan estas rocas en el Pliensbachiano-Toarciano (184-181 Ma), sugiriendo que las rocas serían parcialmente coetáneas con las rocas de la Formación Huemul.

El Batolito Patagónico Cordillerano, por otra parte, comprende los cuerpos plutónicos aflorantes en las zonas más elevadas del sector andino a estas latitudes (Fig. 2). Estos forman parte de un gran cuerpo batolítico que se extiende a lo largo de los Andes Patagónicos, por más de 1500 km, entre los $39^{\circ}$ y los $53^{\circ} \mathrm{S}$. Numerosos estudios señalan que se trata de una unidad intrusiva con una compleja distribución de edades, cuya evolución geológica no ha sido aún completamente esclarecida (Cingolani et al., 1991; González Díaz, 1982; Pankhurst et al., 1992, 1999; Pankhurst y Hervé, 1994; Rapela et al., 1987; Rapela y Kay, 1988).

En el área de estudio, únicamente se observaron contactos por falla de estas plutonitas en relación con las sedimentitas de la Formación Mallín Ahogado (Fig. 3) y a las volcanitas de la Formación Huemul (Figs. 3 y 4). La unidad se dispone en fajas continuas de rumbo norte-sur que limitan la secuencia volcánica jurásica tanto al este como al oeste (Fig. 3).

Las rocas que afloran en el cerro Lindo y en el cerro Hielo Azul se distinguen por sus tonos grisáceos claros, a veces con cierta tonalidad rosada. Se trata de granitoides con grandes cristales de feldespato, caracterizados petrográficamente como monzogranitos. Las plutonitas están atravesadas por numerosos diques de composición básica.

A esta unidad se le atribuía comúnmente una edad jurásica superior a cretácica superior, con el reconocimiento de cuerpos intrusivos cenozoicos a lo largo de su extensión. En este sentido, Pankhurst et al. (1999) reconocieron hasta seis grupos de edades; el registro más antiguo reconocido correspondía al Jurásico Tardío, en el extremo sur del segmento norte (Hervé et al., 2007). Recientemente, Castro et al. (2011) presentaron 14 edades nuevas $\mathrm{U}-\mathrm{Pb}$ SHRIMP obtenidas de circones del Batolito Patagónico Cordillerano inmediatamente al norte del área de estudio y determinaron un intervalo de intrusión entre 170 y 150 Ma (Jurásico Medio-Superior). Al norte, en Paso Puyehue, Aragón et al. (2011) han reportado también edades U-Pb SHRIMP miocenas obtenidas de circones, de 18 y 12.4 Ma, que indican,

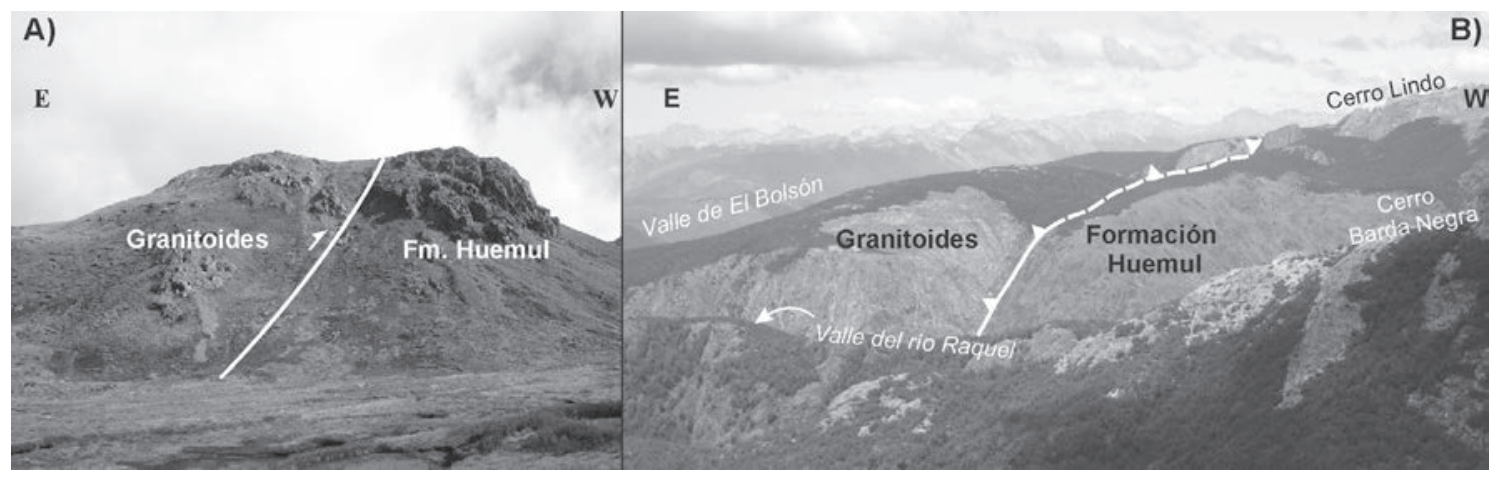

FIG. 4. a. Retrocorrimiento Laguna de Lali, en la vertiente oriental del cerro Lindo, que emplaza una faja de granitoides sobre las secuencias volcanosedimentarias mesozoicas; b. Vista desde el norte del retrocorrimiento Laguna Lali entre el cerro Lindo y el valle del río Raquel (ubicación en figura 7). 
junto con el trabajo de González Díaz (1982), la presencia de cuerpos graníticos cenozoicos en la vertiente argentina de los Andes Norpatagónicos.

\subsection{Formaciones Ventana y Mallín Ahogado (Oligoceno a Mioceno)}

Las unidades cenozoicas que sobreyacen a las rocas plutónicas del Batolito Patagónico Cordillerano corresponden a las formaciones Ventana y Mallín Ahogado (Fig. 3).

El término Formación Ventana fue introducido por González Bonorino (1973) y luego formalmente definido por González Bonorino y González Bonorino (1978). Sin embargo, las primeras descripciones de estas rocas se encuentran vinculadas al reconocimiento temprano de la denominada Serie Andesítica, definida por Feruglio (1927). El término informal Serie Andesítica ha tenido un notable arraigo en la comunidad geológica argentina a pesar de que no se recomienda su uso dado que abarca, en la región patagónica, volcanitas de muy variadas edades, que van desde cretácicas inferiores hasta rocas paleógenas y miocenas (Rapela et al., 1983).

Ramos (1982) reactualizó la distinción de dos fajas, una andina y otra extrandina. Rapela et al. (1988) han descrito las dos fajas volcánicas reconociendo el cinturón interno de El Maitén y el cinturón externo de Pilcaniyeu, correlacionables con las formaciones Ventana y Huitrera respectivamente.

Rocas asignadas a la Formación Ventana afloran en el cerro Silvia (Fig. 3). Se trata de una secuencia monótona de tobas intercaladas con coladas basálticas, atravesada por numerosos diques de idéntica composición. La sucesión se halla en relación tectónica respecto de las rocas jurásicas que afloran en el cerro Hielo Azul.

Estas rocas afloran al norte, en el cerro Bastión, por lo que fueron también definidas como Formación Cerro Bastión por Diez y Zubia (1981). Allí se reconocen aglomerados volcánicos andesíticos (Diez y Zubia, 1981), en un perfil que alcanzaría los 1000 m. González Bonorino y González Bonorino, (1978; p. 185) reconocieron en el cerro Ventana, su localidad tipo (3.500 m de lavas, brechas, tobas y 'wackes').

En cuanto a la edad de esta unidad, se cuenta con diecisiete edades K-Ar entre los 34 y los 24 Ma (Cazau et al., 1989), que permiten ubicar la Formación Ventana en el Oligoceno.
La Formación Mallín Ahogado fue definida por Diez y Zubia (1979)² y abarca las rocas sedimentarias cenozoicas que afloran en la depresión de El Bolsón entre los $41^{\circ} 30^{\prime}$ y $42^{\circ} \mathrm{S}$ (Fig. 2) (Giacosa et al., 2001). Bajo esta denominación, se incluyen las 'Lutitas del Río Foyel' (Bertels, 1980), la Formación Rincón de Cholila (Cazau, 1972), la Formación Río Foyel (Pöthe de Baldis, 1984) y distintas sedimentitas que afloran en los cordones Serrucho y Piltriquitrón, el valle del río Foyel, en la localidad de Río Villegas, al norte del cerro Santa Elena, en el cerro Montura o El Foyel y sobre el faldeo oriental del cerro Perito Moreno (Fig. 2) (Giacosa et al., 2001), así como también al Grupo El Foyel (Asensio et al., 2005, 2010).

Estas sedimentitas cenozoicas forman parte del relleno de la cuenca de Ñirihuau, conformando una subcuenca occidental que resultó desconectada de la cuenca principal durante el Neógeno. En este sentido, las rocas fueron caracterizadas bajo la denominación de Formación Ñirihuau y equivalentes por Spalletti (1983).

En los alrededores de El Bolsón, la Formación Mallín Ahogado se encuentra en contacto por falla, al oeste con las rocas del Batolito Patagónico Cordillerano (Fig. 3) y al este con las rocas de la secuencia volcanoclástica jurásica mediante el sistema de retrocorrimientos Piltriquitrón (Giacosa et al., 2001). $\mathrm{Al}$ norte, la formación se asienta en discordancia erosiva sobre las plutonitas del Batolito Patagónico Cordillerano o sobre las rocas volcánicas de la Formación Huemul, mediando un fuerte paleorrelieve (foto 5 de Giacosa et al., 2001).

Las rocas constituyen un conjunto sedimentario marino-continental. En la Loma del Medio (Fig. 2), Diez y Zubia (1981) reconocieron dos secciones. La inferior, marina, comprende un conglomerado basal polimíctico al que siguen pelitas y areniscas finas bien estratificadas; sobre el río Azul, a 2 km aguas arriba del arroyo Teno (Fig. 3), esta sección tiene 150 m. La sección superior cubre transicionalmente a la anterior y comienza con $170 \mathrm{~m}$ de areniscas y pelitas con presencia de materia carbonosa, a la que siguen areniscas, pelitas, conglomerados, tobas y tufitas intercaladas. Un espesor máximo de $500 \mathrm{~m}$ se puede observar a la latitud de Cascada Escondida (Diez y Zubia, 1981; p. 25).

Spalletti y Matheos (1987), al analizar la composición de las sedimentitas, concluyen que los litoclastos son claramente los componentes más abundantes, mientras que el aporte de unidades

2 Diez, O.; Zubia, M. 1979. Informe preliminar de la Hoja 41a, El Bolsón, provincia de Río Negro (inédito). Servicio Minero Nacional, Plan Patagonia Comahue. Comodoro Rivadavia. 
plutónicas es prácticamente nulo, y que dichos litoclastos revelan un aporte de rocas volcánicas y piroclásticas intermedias y ácidas derivadas de las fajas volcánicas paleógenas -Pilcaniyeu y El Maitén-, y/o de las volcanitas jurásicas.

Determinaciones de edad basadas en el contenido fosilífero de las unidades sedimentarias mencionadas han permitido proponer para esta unidad una edad eocena (Ubaldón, 1981³; Chiesa y Camacho, 2001), oligocena (Bertels, 1980; Griffin et al., 2004), oligocena inferior a miocena inferior (Barreda et al., 2003), miocena inferior (Asensio et al., 2010). Recientemente, Encinas et al. (2010) presentaron dataciones U-Pb (LAICPMS) realizadas en circones detríticos de areniscas obtenidas en el puesto de Gendarmería de río Villegas de la Formación Río Foyel (Pöthe de Baldis, 1984) y en el cerro Plataforma que indican edades máximas de sedimentación entre 21 y 17 Ma, situando a estos depósitos en el Mioceno.

\section{Estructura de la faja plegada y corrida de la Cordillera Norpatagonica al norte de los $42^{\circ} \mathrm{S}$}

Los Andes Patagónicos de Río Negro se caracterizan por el desarrollo de una faja plegada y corrida (Ramos, 1981; Ramos y Cortés, 1984) de rumbo meridiano, que hacia el norte vira al NW, por un control de estructuras del basamento (Giacosa y Heredia, 2004; García-Sansegundo et al., 2009). Esta faja de deformación está conformada por una serie de corrimientos con vergencia general hacia el este y un sistema retrovergente interpuesto en su sector oriental (Giacosa y Heredia, 2004). Tal como fuera señalado por Ramos y Cortés (1984), pueden distinguirse dentro de la misma dos sectores o dominios principales en función de las estructuras predominantes y de las unidades involucradas en la deformación: al oeste, un sector interno con predominio de fallamiento que afecta mayormente a rocas preterciarias, y al este, un sector externo en el que predominan sedimentitas y volcanitas terciarias, conformando importantes fajas de plegamiento (Giacosa y Heredia, 2004).

El límite entre ambos dominios corresponde a la traza del corrimiento Ventana-Catedral (Giacosa y Heredia, 2004) (Fig. 2). El sector frontal de la faja plegada y corrida emergería en la región de Río Chico, a unos $90 \mathrm{~km}$ del eje cordillerano, donde afloran rocas metamórficas del Neopaleozoico, limitando la expansión hacia el este de los depósitos sinorogénicos neógenos (Giacosa y Heredia, 2004).
A escala local, el perfil estructural del valle de El Bolsón realizado por Giacosa y Heredia (2004) permite reconocer: a. al oeste, un corrimiento de primer orden (Bolsón-Tronador) que levanta el cordón del Hielo Azul, con importante desarrollo hacia el norte; el mismo sobrepone los granitoides del Batolito Patagónico Cordillerano por sobre las sedimentitas cenozoicas de la Formación Mallín Ahogado; b. un sinclinal cuyo eje coincide con la orientación del valle, desarrollado sobre las sedimentitas de la Formación Mallín Ahogado; y c. una serie de retrocorrimientos que levantan el cordón del Piltriquitrón, cabalgando las rocas jurásicas por sobre las sedimentitas cenozoicas del sector este del valle (Giacosa y Heredia, 2004; Figs. 3 y 5).

El sinclinal tiene un eje buzante al norte, con el cierre periclinal ubicado en el extremo sur de la Loma del Medio. Esta estructura es interpretada como producto de la interacción de sistemas compresivos de vergencia opuesta, en lo que representaría la expresión superficial de una zona triangular (sensu McClay, 1999) en el subsuelo (Giacosa y Heredia, 2004).

En los trabajos mencionados (Giacosa et al., 2001; Giacosa y Heredia, 2004), la Cordillera Patagónica es representada como un bloque exhumado por una falla que inclina al oeste, el corrimiento Bolsón-Tronador (Figs. 2 y 3). Sin embargo, las observaciones de campo permiten interpretar una mayor complejidad estructural.

Al oeste del corrimiento Bolsón-Tronador (Fig. 3), la pendiente empinada del cerro Lindo se halla labrada sobre los granitoides del Batolito Patagónico Cordillerano, que se reconoce a través de afloramientos reducidos y discontinuos entre la vegetación. A la altura del refugio Cerro Lindo (a 1500 m s.n.m.) se distinguen los granitoides del Batolito Patagónico Cordillerano, conformando un importante paredón rocoso de unos $100 \mathrm{~m}$ de desnivel.

$\mathrm{Al}$ este de este quiebre topográfico, se observa que los granitoides están corridos por encima de las rocas andesíticas oscuras de la Formación Huemul por un retrocorrimiento que inclina unos $40^{\circ}$ al este, el cual fue denominado retrocorrimiento Laguna de Lali (Fig. 4A).

En la figura 3, puede observarse que la traza de este retrocorrimiento presenta una forma cóncava hacia el este, entre la inflexión de $90^{\circ}$ que presenta el río Azul al norte de El Bolsón y la localidad de Lago Puelo al sur. 


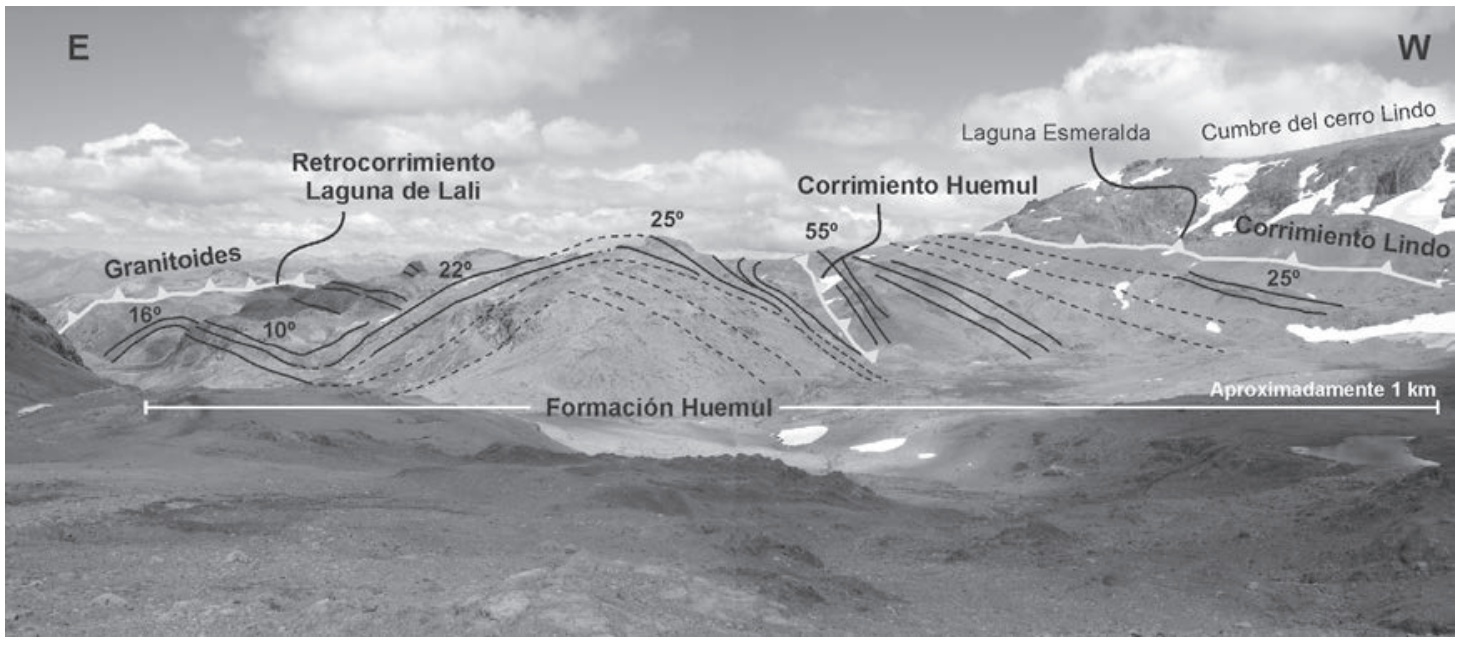

FIG. 5. Faja de deformación entre el retrocorrimiento Laguna Lali (Fig. 4) y el corrimiento fuera de secuencia que exhuma el frente oriental del Batolito Patagónico (este último se encuentra inmediatamente al oeste de la foto; Fig. 6). Esta faja afecta a las volcanitas mesozoicas de la Formación Huemul. Nótese la corta longitud de onda de los pliegues (ubicación en figura 7). Vista desde el norte.

Al oeste del retrocorrimiento Laguna de Lali, afloran las rocas jurásicas, las que se extienden hasta la laguna de deshielo Esmeralda, situada al pie de la cumbre del cerro Lindo (véanse las Figs. 3 y 5). A lo largo de unos $750 \mathrm{~m}$, se reconocieron diferentes dominios de inclinación en la secuencia, que permiten interpretar la existencia de dos anticlinales y un sinclinal: los estratos inclinan $16^{\circ}$ al este en la proximidad del retrocorrimiento Laguna de Lali; luego adquieren una inclinación $10^{\circ}$ al oeste, de $22^{\circ}$ al este y, finalmente, de $25^{\circ}$ al oeste (Fig. 5). La pequeña longitud de onda de las estructuras implica un despegue común relativamente superficial.

En la imagen satelital 'Ikonos' tomada del 'software Google Earth’, pareciera observarse una morfología característica de pliegues concéntricos, como aquellos producidos por flexión de los estratos en el bloque de techo y relacionados con rampas de falla o bien por cambios en la inclinación de los planos de falla, lo que coincidiría con lo descrito en el cordón del Piltriquitrón por Giacosa y Heredia (2004).

Hacia el oeste fueron reconocidos otros dos corrimientos, afectando la secuencia jurásica, y que delimitan la faja de pliegues al oeste (Fig. 3). El corrimiento Huemul transporta una lámina compuesta por las volcanitas jurásicas, con bancos que inclinan $55^{\circ}$ al oeste (Fig. 5). El corrimiento 'Cerro Lindo' se asocia al quiebre topográfico oriental del cerro homónimo a la altura de la laguna Esmeralda (Fig. 3).
La sección de rocas volcánicas culmina con una sucesión de piroclastitas correspondientes a los términos más altos de esta unidad (Diez y Zubia, 1981). Hacia el oeste, la sección volcánica resulta truncada por un corrimiento fuera de secuencia 'out of sequence thrust' que cabalga hacia el este los granitoides del Batolito Patagónico Cordillerano. La falla, que coincide con la abrupta hondonada que divide los cerros Lindo y Alicia, corta la secuencia de volcanitas jurásicas previamente deformadas (Fig. 6).

Un perfil completo de esta sección volcánica puede observarse a lo largo del filo que limita los lagos Tricolor y Lindo hacia el norte (Fig. 6). En el mismo, es posible reconocer algunas de las estructuras antes señaladas, aunque en general no ha sido posible establecer una correlación directa entre los distintos dominios de inclinación, a pesar de que la traza de las fallas parece tener continuidad hacia el norte. En el caso concreto de las estructuras plegadas, es posible inferir, ya que se trata de estructuras muy superficiales, que las mismas pierden continuidad espacial hacia el norte.

Los corrimientos Huemul y Cerro Lindo se reconocen con claridad hacia el norte. La traza de este último se une al corrimiento fuera de secuencia (OST; Fig. 6) y continuaría al norte a través del corrimiento Hielo Azul (Giacosa y Heredia, 2004).

En el refugio Laguna Natación del cerro Hielo Azul, se ha interpretado la existencia de un corri- 


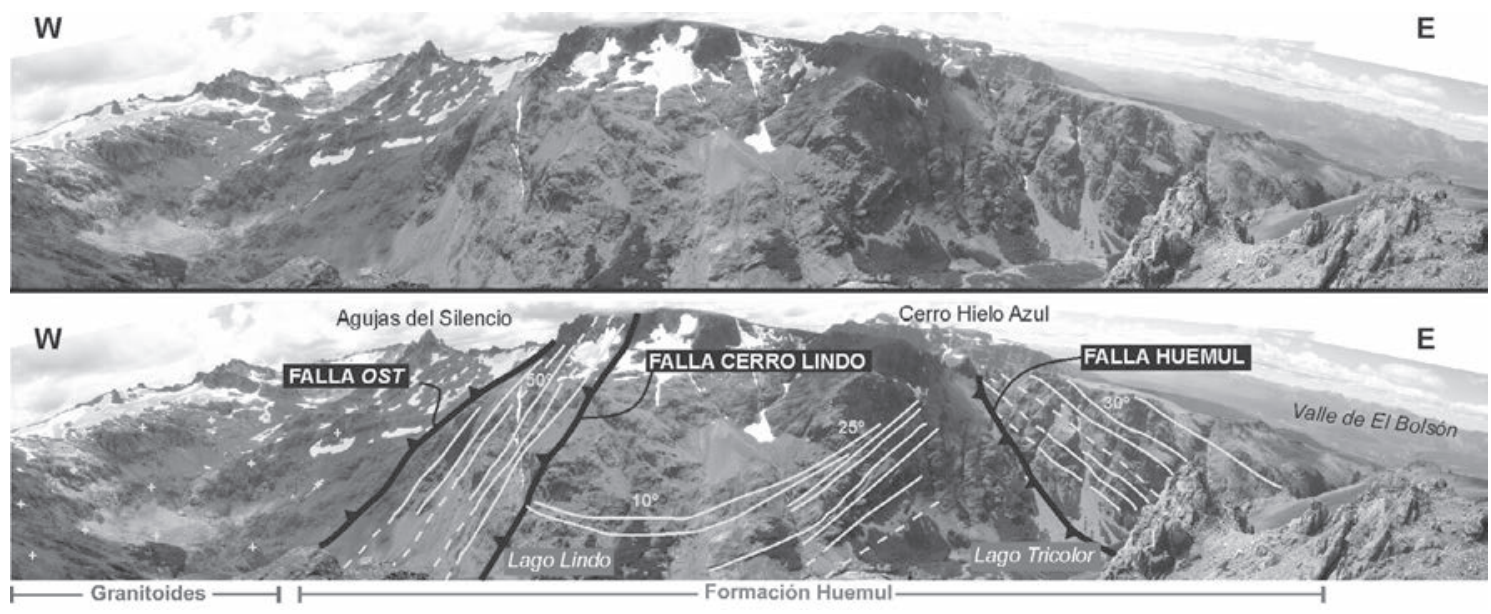

FIG. 6. Faja de deformación que afecta a la Formación Huemul al norte del cerro Lindo y su relación con el corrimiento occidental (OST) que emplaza al Batolito Patagónico Cordillerano sobre las volcanitas jurásicas (ubicación en figura 7B). La falla Huemul inclina hacia el oeste y no al este, como pareciera en la figura por la perspectiva con la que se tomó la fotografía. Vista hacia el norte.

miento denominado Laguna Natación, que transporta una lámina jurásica con vergencia hacia el este. Los bancos se hallan muy deformados y erosionados en el frente de la estructura, lo que dificulta la observación de su actitud; se interpreta que los mismo yacen verticalmente, en tanto que hacia el oeste se tornan más tendidos, inclinando $30^{\circ}$ hacia el oeste (Fig. 3). No se cuenta aún con observaciones precisas respecto de la posición de los bancos más occidentales de la secuencia, aunque se ha interpretado la existencia de dos corrimientos que transportarían láminas de volcanitas, tal como sucede al sur.

Las distintas estructuras identificadas en el cordón del Hielo Azul han sido representadas en la figura 7. En la misma, puede verse que el corrimiento Hielo Azul, que constituye el límite occidental de la Formación Huemul, sobrepone las rocas cenozoicas de la Formación Ventana por sobre las volcanitas jurásicas (Fig. 8). Este corrimiento había sido reconocido previamente por Giacosa y Heredia (1999, 2004), pero es descrito aquí por primera vez.

Las rocas aflorantes en el cerro Silvia fueron asignadas a la Formación Ventana por Giacosa et al. (2001). Los afloramientos analizados en este estudio forman parte del sector más oriental del cerro. Allí, los estratos se disponen con un acimut de $125^{\circ} \mathrm{e}$ inclinan $42^{\circ}$ al NE. Cabe destacar que los bancos son más potentes hacia el este, contra la falla, y permiten definir una cuña de sinrift (Fig. 8). Esto es particularmente visible hacia el tope de la secuencia, y permite inferir una depositación sinextensional, en lo que habría constituido un pequeño y aislado depocentro terciario en el sector cordillerano. Los márgenes norte y sur de dicha cubeta se encuentran cubiertos por la vegetación, y coincidirían con el cauce de los ríos Azul y Raquel respectivamente (Fig. 3).

En el sector más occidental del cerro Silvia se interpreta, a partir de imágenes satelitales y de fotos obtenidas desde la cumbre del cerro Hielo Azul, que los bancos inclinarían hacia el SW. Si esta presunción es cierta, las rocas de la Formación Ventana conformarían un anticlinal en el cerro Silvia. Más importante aún, esta estructura revelaría la existencia de un episodio contraccional posoligoceno que plegó a las volcanitas, posiblemente vinculado con la inversión de la falla normal (que controló la formación del depocentro) que dio lugar finalmente al corrimiento Hielo Azul, sobreponiendo las rocas cenozoicas por sobre las volcanitas jurásicas.

En la figura 9, se representaron los perfiles estructurales A-A' (cerro Lindo-Alicia) y B-B' (cerro Hielo Azul-Silvia), que resumen la información estructural del cordón del Hielo Azul.

\section{Construcción de la sección balanceada}

A partir de los datos estructurales y geológicos recogidos en el campo en el Cordón del Hielo Azul, y de los datos de inclinación de los estratos terciarios en el valle de El Bolsón y el cordón 

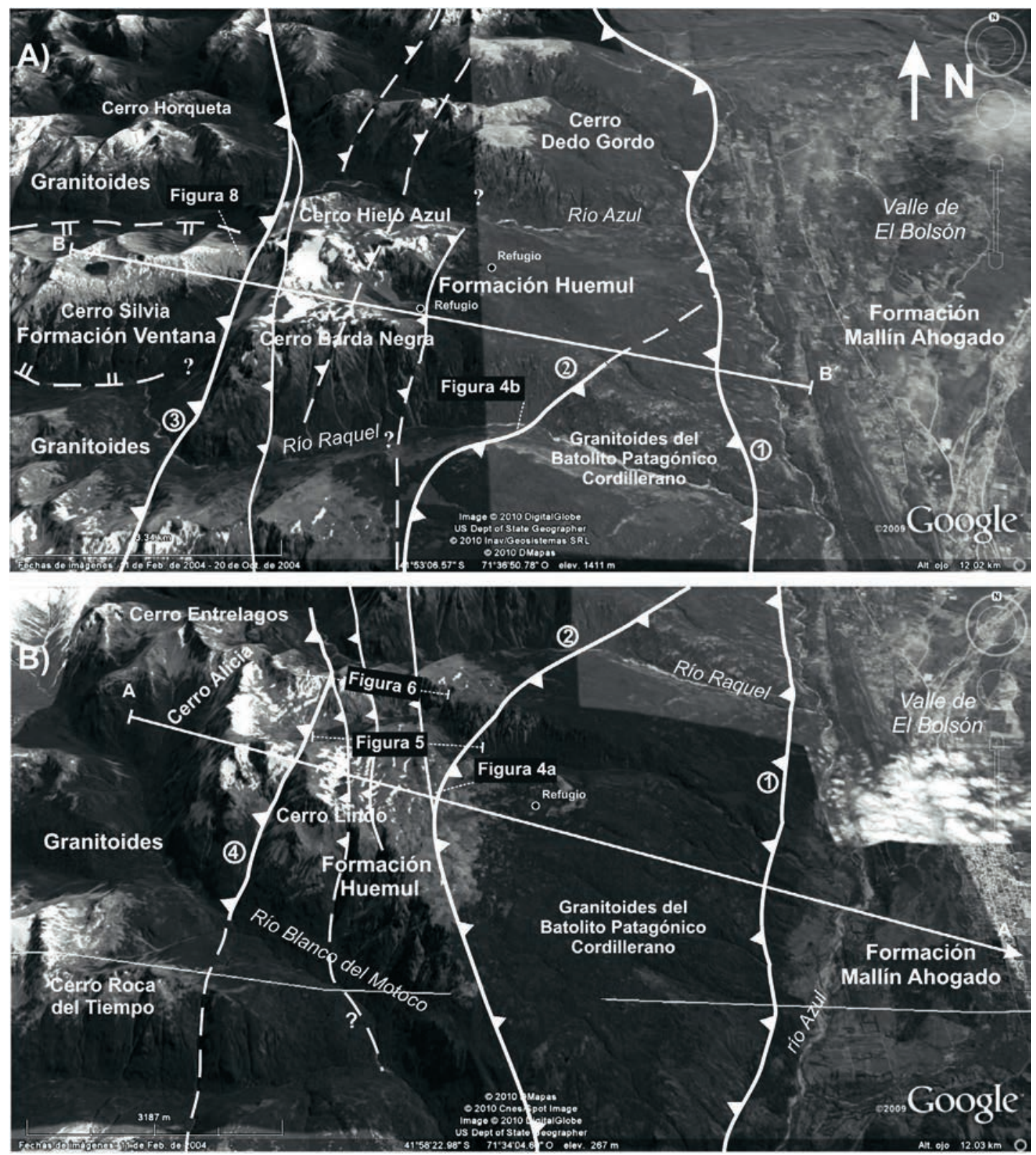

FIG. 7. Principales estructuras descritas en el trabajo, representadas en una vista 3D construida a partir de un DEM sobre el cual se proyectaron imágenes ‘Ikonos’ (tomado del ‘software’ Google Earth). A) Sector norte del cordón del Hielo Azul (cerro Hielo Azul-cerro Silvia); B) sector sur del cordón del Hielo Azul (cerro Lindo-cerro Alicia). Se han numerado algunos de los corrimientos para facilitar la continuidad entre ambas imágenes: 1. Corrimiento Bolsón-Tronador; 2. Retrocorrimiento Laguna de Lali; 3. Corrimiento Hielo Azul; 4. Corrimiento fuera de secuencia. Se ha representado, además, la traza imaginaria A-Á y B-B' de los perfiles estructurales representados en la figura 9.

del Piltriquitrón provistos por Giacosa y Heredia (2004), se confeccionó una transecta estructural A-A' a los $41^{\circ} 50$ 'S aproximadamente, con el objetivo de estimar valores de acortamiento y poder así comprender mejor la mecánica de deformación del sistema andino a estas latitudes.

En primer lugar, se reconstruyó la estructura de piel fina identificada sobre el sector occidental, 


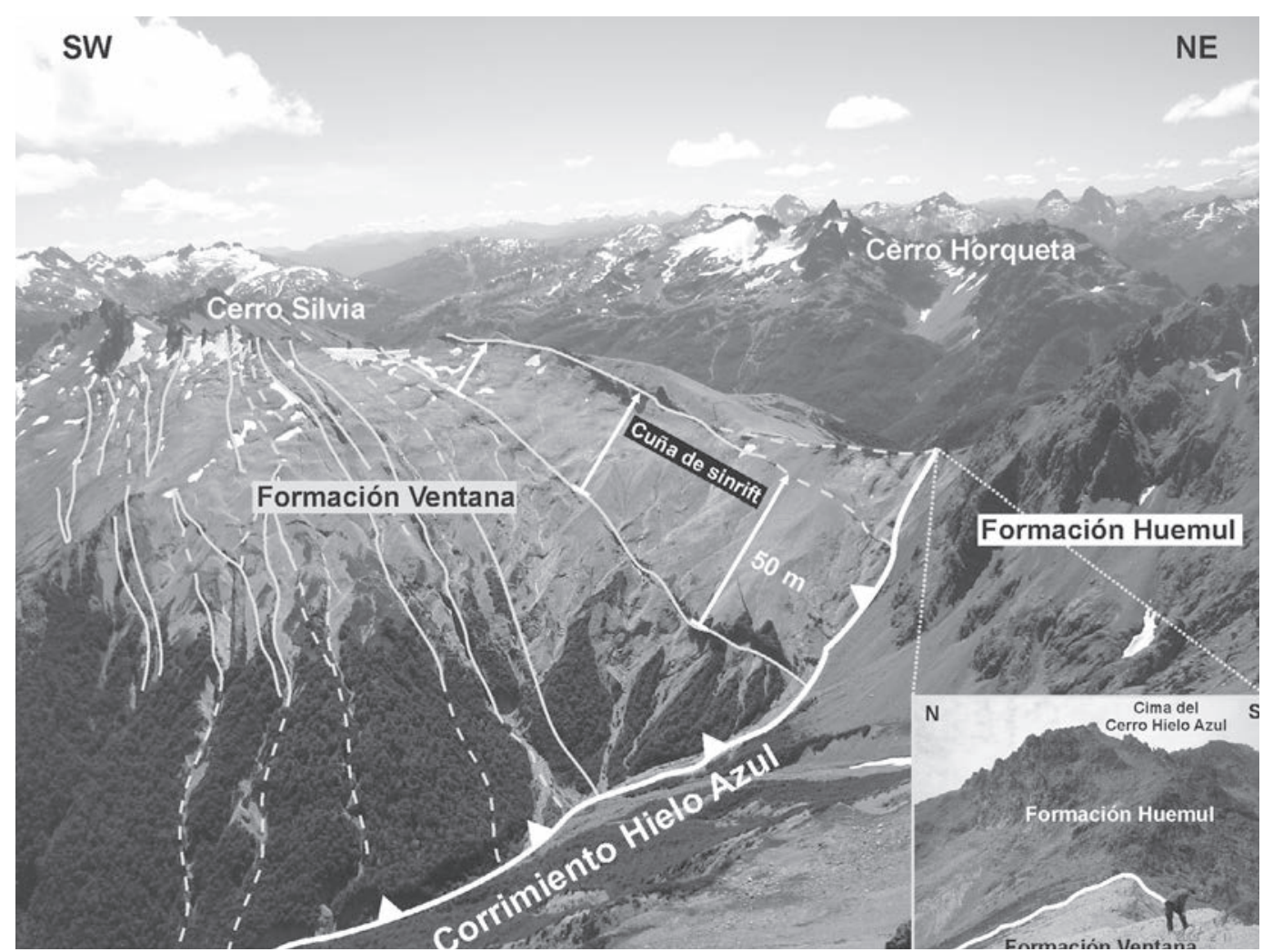

FIG. 8. Cabalgamiento que sobrepone las volcanitas oligocenas del cerro Silvia (Formación Ventana) por sobre las secuencias volcanosedimentarias mesozoicas del cerro Hielo Azul (Formación Huemul), definiendo una relación normal (ubicación en figura 3). Las volcanitas conforman una secuencia monótona de potentes bancos de tobas con intercalación de lavas basálticas. Hacia el fondo (al norte), el cerro Horqueta, conformado por granitoides del Batolito Patagónico, es levantado por la continuación de esta estructura a través de su faldeo oriental (valle del río Rayado). Vista desde el SE.

en el cerro Lindo, utilizando el cálculo propuesto por Epard y Groshong (1993) para estimar niveles de despegue en fajas epidérmicas. Posteriormente, sobre la base de las geometrías de Suppe (1983), se reconstruyeron los sistemas de corrimientos Cerro Lindo y Huemul; para ello, se utilizó el algoritmo 'fault parallel flow' del ‘software 2DMove' (Kane et al., 1997; Egan et al., 1997). El desplazamiento de la falla de basamento (OST) que levanta el cerro Alicia fue restituido, utilizando también el algoritmo 'fault parallel flow' (Kane et al., 1997; Egan et al., 1997).

El sector desarrollado entre el corrimiento Huemul y el retrocorrimiento Laguna de Lali, donde se observaron pliegues de muy corta longitud de onda, fue restituido utilizando el algoritmo 'flexural slip’ presente del ‘software 2DMove' (Kane et al., 1997; Egan et al., 1997), al igual que las estructuras presentes del valle de El Bolsón.
Las estructuras de basamento -retrocorrimiento Laguna de Lali y corrimiento Bolsón-Tronadory aquellas presentes en el sector occidental del cerro Piltriquitrón fueron restituidas utilizando el algoritmo 'fault parallel flow' (Kane et al., 1997; Egan et al., 1997).

El sector oriental de la sección estructural correspondiente al valle de El Bolsón y Cordón del Piltriquitrón se representó sobre la base del esquema propuesto por Giacosa y Heredia (2004). En todos los casos, la geometría de las fallas en profundidad resulta especulativa, ya que no existen datos sísmicos o de gravedad que permitan constreñir dichas geometrías en el subsuelo.

La figura 10 muestra la restitución de la sección estructural. El acortamiento calculado es de 4,47 $\mathrm{km}$, lo cual representa un $21 \%$ de acortamiento. Como se puede observar, la sección estructural 
w

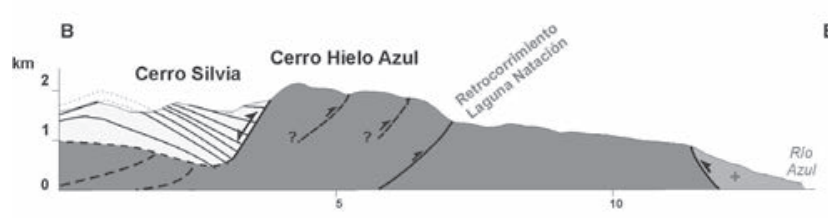

E

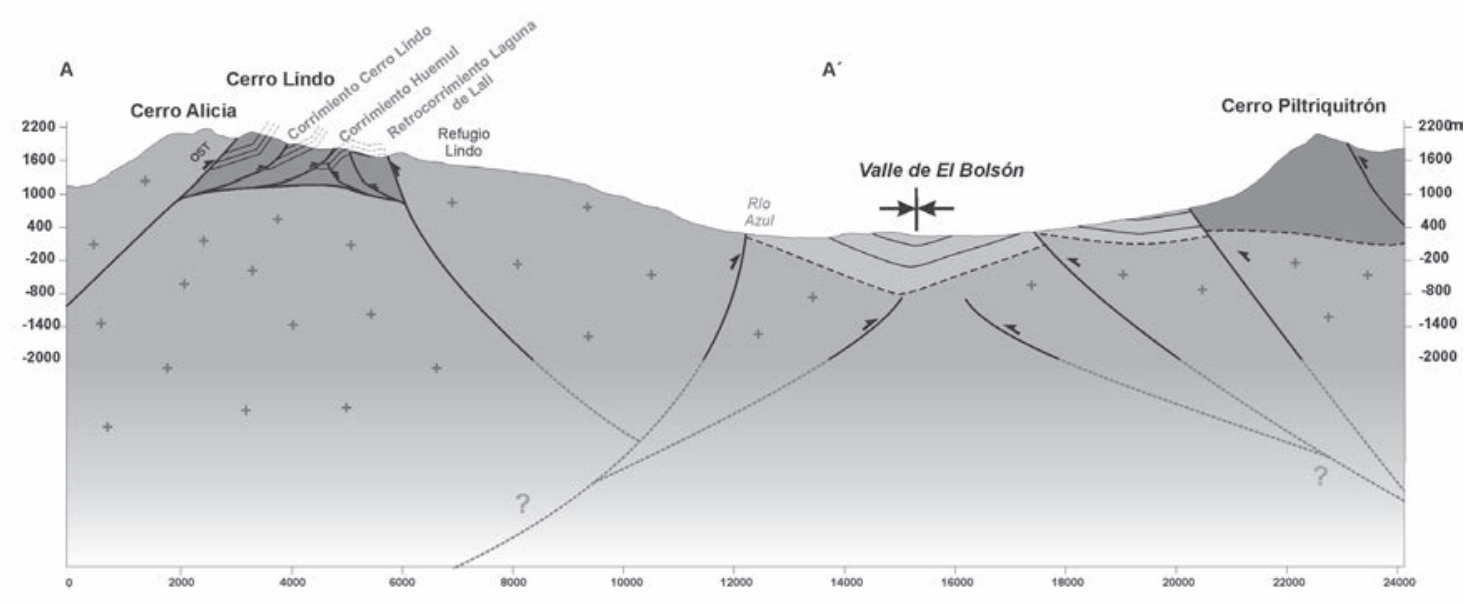

FIG. 9. Perfiles estructurales a la altura del cerro Hielo Azul y cerro Lindo, dibujados a la misma escala (ubicación en figura 7). Nótese que el corrimiento fuera de secuencia que exhuma al Batolito Patagónico al sur es reemplazado por una falla normal invertida hacia el norte, que exhuma un depocentro paleógeno con las volcanitas de la Formación Ventana. Nótese que la zona de deformación que afecta a la secuencia volcánica mesozoica en el cerro Lindo, interpretada como asociada a un despegue superficial, es reemplazada al norte por un abanico de estructuras que penetran en el basamento.

muestra el desarrollo de un sistema de piel fina producido a expensas de la secuencia jurásica del Cordón del Hielo Azul, el cual concentraría aproximadamente un $70 \%$ del acortamiento total registrado. Las estructuras presentes al este, por otra parte, se originan en un nivel de despegue profundo, lo que implica una deformación de piel gruesa: se trata de fallas de basamento con alto ángulo que acomodan poco acortamiento, como se deduce de la participación que éstas tienen en el acortamiento total estimado.

\section{Discusión}

Las rocas más antiguas aflorantes en el área de estudio son las volcanitas de la Formación Huemul, que forman parte de un conjunto volcanosedimentario cordillerano de extensión regional del Jurásico Temprano. Los datos de campo presentados en este estudio, sumados a los de Diez y Zubia (1981), ponen de manifiesto que las volcanitas son la litología dominante en el ámbito de la Cordillera Patagónica.

Se ha postulado que este conjunto volcanosedimentario cordillerano podría haberse emplazado en una gran cuenca extensional o transtensional abierta hacia el oeste, que habría funcionado hasta el Cretácico Temprano (Giacosa y Heredia, 2000); el límite oriental de la cuenca coincidiría con el corrimiento López, que en la actualidad opone lateralmente la secuencia volcanosedimentaria respecto del Batolito Subcordillerano, y sería una falla normal invertida durante el Cenozoico; la cuenca se habría desarrollado durante una etapa previa al ciclo andino dentro de un régimen tectónico extensional, desarrollando estructuras de tipo ‘horst y graben' (Giacosa y Heredia, 2000). Recientemente Castro et al. (2011) han sugerido la existencia de una falla de rumbo sinistral, de escala regional, que controló el emplazamiento de los granitoides del Batolito Patagónico Cordillerano durante el Jurásico Medio-Tardío. 


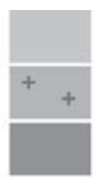

Formación Mallín Ahogado

Batolito Patagónico Cordillerano

Formación Huemul

W
E

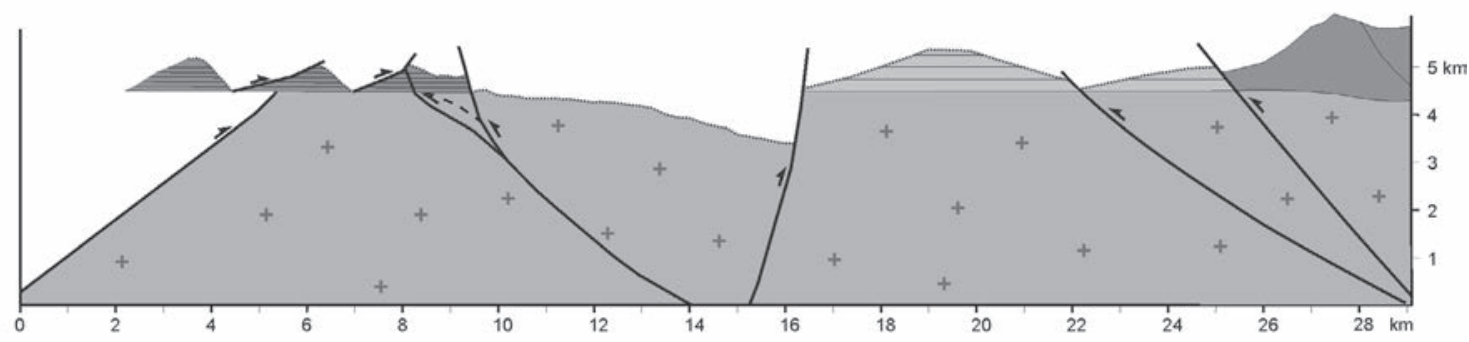

$26,22 \mathrm{~km}$

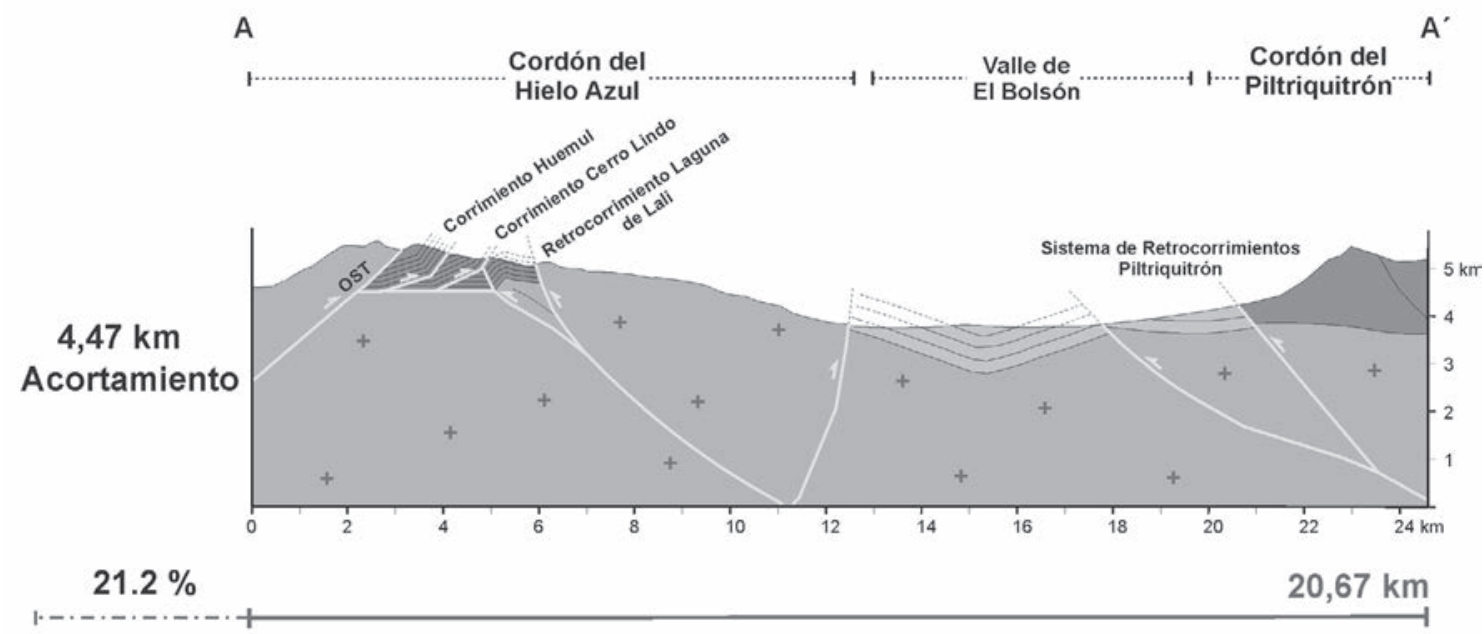

FIG. 10. Perfil balanceado entre el cordón del Hielo Azul y el cordón del Piltriquitrón.

En cuanto al comienzo del ciclo compresivo, al norte, en sectores andinos de Chile y Argentina, se han presentado evidencias respecto de un pulso de deformación compresiva desarrollado con anterioridad al Paleoceno, quizás hacia fines del Cretácico Tardío (Cornejo et al., 2003; Charrier et al., 2007; Zamora Valcarce et al., 2009; Tunik et al., 2010). Al sur también se han encontrado evidencias de deformación contraccional prepaleocena. Suárez y Márquez (2007) han reconocido un evento contraccional (o transpresional) del Jurásico inferior que afectó a la Formación Osta Arena, en la cuenca de Chubut (sensu Suárez y Márquez, 2007) desarrollada al este del Batolito Patagónico Cordillerano. Suárez y De La Cruz (2000) interpretan una fase de tectonismo contraccional que tuvo lugar entre el pos-Barremiano y el Paleoceno tardío, al sur del Lago General Carrera.

No obstante esto, en este sector de la Cordillera Norpatagónica no existen aún evidencias que permitan asegurar que el ciclo compresivo andino haya comenzado con anterioridad al Paleoceno.

La detallada descripción que se hizo de las estructuras en el cordón del Hielo Azul pone de manifiesto que la deformación en el área progresó 
a través de -al menos- dos pulsos: a. un pulso de deformación epidérmica o de piel fina ('thin-skinned fold and thrust belt') (Rodgers, 1971), representado por pliegues y los corrimientos Huemul, Cerro Lindo y Laguna Natación que afectan internamente a la Formación Huemul y definen una faja plegada y corrida exhumada y canibalizada; b. un pulso de deformación caracterizado por estructuras profundas con un despegue localizado en el basamento de deformación de piel gruesa ('thick-skinned fold and thrust belt') (Rodgers, 1971), que incluye el retrocorrimiento Laguna de Lali y posiblemente el corrimiento fuera de secuencia que limita la secuencia volcánica al oeste, ambas estructuras reconocidas por primera vez aquí, junto a los corrimientos Hielo Azul y Bolsón-Tronador previamente identificados por Ramos y Cortés (1984) y Giacosa et al., 2001).

En este trabajo se interpreta que la Formación Ventana, emplazada en discordancia angular sobre la secuencia jurásica deformada en el cordón del Hielo Azul, determina una edad mínima oligocena para la deformación epidérmica que afectó la secuencia volcánica cordillerana, que pudo así haber tenido lugar entre el Cretácico Temprano y el Eoceno.

La cuña de 'sinrift' que define la secuencia volcánica terciaria en el cerro Silvia estaría indicando que en la evolución tectónica del área existió una fase extensional durante el desarrollo del volcanismo del Oligoceno. Esta fase extensional ha sido descrita por Muñoz et al. (2000) en territorio chileno como un episodio regional de atenuamiento cortical asociado a la formación de cuencas sedimentarias, tanto al oeste como al este de la Cordillera Patagónica; esta interpretación resulta coherente con el carácter extensional que Rapela et al. (1988) asignaron a las rocas del Cinturón de El Maitén. El conjunto de edades presentado por Muñoz et al. (2000) circunscribe el evento entre los $29 \mathrm{Ma}$ (Oligoceno Superior) y los 18,8 Ma (Mioceno Inferior), y es compatible con las edades de la Formación Ventana existentes a la fecha.

La deformación de piel gruesa que caracteriza al segundo pulso de deformación planteado, representaría el avance de la deformación hacia el este. Se relacionan con este avance estructuras de primer orden, como el corrimiento Hielo Azul que invierte el depocentro del actual cerro Silvia, el corrimiento Bolsón-Tronador que eleva el cordón del Hielo Azul y los retrocorrimientos que estructuran los cordones Serrucho y Piltriquitrón, correpondientes al sistema de retrocorrimientos Piltriquitrón (Giacosa et al., 2001), siendo estas dos últimas estructuras de vergencia opuesta, las que determinaron el desarrollo de una zona triangular, cuya expresión superficial es el valle tectónico de El Bolsón.

Un dato interesante que surge del análisis de la composición de las sedimentitas de la Formación Mallín Ahogado en el valle de El Bolsón que realizaron Spalletti y Matheos (1987), es el que establece que el aporte del Batolito Patagónico Cordillerano a las sedimentitas miocenas inferiores es nulo o despreciable, por lo que los autores concluyen que los granitoides no habían sido aún exhumados. Este dato apoyaría la hipótesis de un pulso contraccional pos-Mioceno Temprano que involucró al basamento y controló la exhumación, como el descrito anteriormente para el área de estudio, y que dio lugar al desarrollo de una faja plegada y corrida de piel gruesa.

Las consideraciones anteriores en cuanto a los pulsos de deformación y las estructuras que involucran, junto con sus posibles edades se encuentran esquematizadas en la figura 11.

\section{Conclusiones}

El estudio detallado del sector interno de la faja plegada y corrida andina a los $42^{\circ} \mathrm{S}$, permite interpretar una evolución estructural más compleja que aquella señalada en los antecedentes.

Se reconoció la existencia de una faja plegada y corrida fósil desarrollada a expensas de un despegue en las volcanitas jurásicas de la Formación Huemul.

En el cerro Silvia hay evidencias de: a. acumulación de las volcanitas de la Formación Ventana controlada por una falla normal; b. posterior inversión posoligocena a través del corrimiento Hielo Azul.

Estas evidencias reafirman dos aspectos fundamentales de la evolución tectónica de este sector andino: a. el volcanismo oligoceno fue controlado por un régimen extensional; b. la inversión tectónica de fallas normales habría actuado como mecanismo de generación de relieve en los sectores más internos de la faja plegada y corrida.

Se estableció una cronología de deformación preliminar hasta que se cuente con edades precisas de las distintas unidades y de los pulsos deformacionales que estructuraron la cordillera. Un pulso contraccional preoligoceno deformó las volcanitas jurásicas que actualmente afloran en el Cordón del Hielo Azul, configurando una faja plegada y corrida de piel fina. Luego, durante el Oligoceno 
y quizás a comienzos del Mioceno, tuvo lugar un evento extensional que dio lugar al desarrollo del depocentro en el que se depositaron las volcanitas de la Formación Ventana. Hacia el Mioceno Medio a Tardío, finalmente, un nuevo evento compresivo posibilitó el desarrollo de una faja plegada y corrida de piel gruesa, responsable del levantamiento de los principales cordones montañosos que hoy en día limitan el valle de El Bolsón, así como también de la deformación de las sedimentitas allí acumuladas.

Los datos estructurales obtenidos en el cordón del Hielo Azul fueron integrados con aquellos disponibles hacia el este en el área de El Bolsón, y con toda la información se confeccionó la primera sección balanceada para este sector interno de la faja plegada y corrida de Río Negro.

La sección A-A' realizada a lo largo del cordón de Hielo Azul y del valle de El Bolsón permitió obtener por primera vez un dato del acortamiento que habría sufrido este sector de la Cordillera Norpatagónica. De los 4,5 km de acortamiento estimados, un $70 \%$ se halla absorbido en la deformación de piel fina que afectó a las volcanitas jurásicas de la Formación Huemul con anterioridad al Oligoceno.

\section{EVOLUCIÓN ESTRUCTURAL DEL CORDÓN DE HIELO AZUL}

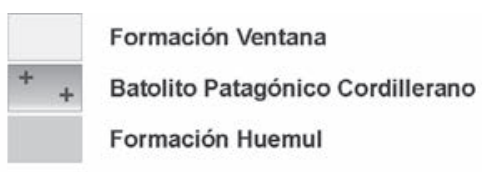

E

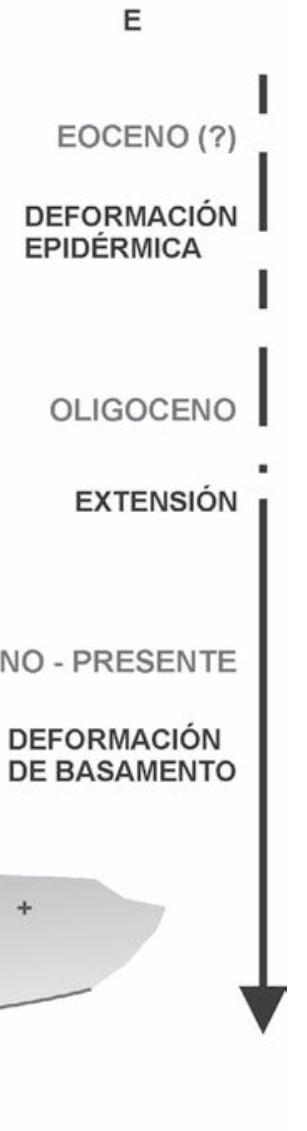

FIG. 11. Evolución temporal de las estructuras en el cordón del Hielo Azul. Fallas representadas: 1 y 2, corrimientos Cerro Lindo y Huemul; 3, OST, falla fuera de secuencia con vergencia al este; 4, retrocorrimiento Laguna de Lali. Entre las fallas 1, 2 y 3 , y la falla 4, se habrían depositado las volcanitas de la Formación Ventana. 


\section{Agradecimientos}

Este trabajo forma parte del proyecto de investigación titulado ‘Evolución tectónica de los Andes entre los 39³0' y los $43^{\circ} \mathrm{S}$ : definición de etapas contraccionales y fases de desestabilización orogénica en los Andes Norpatagónicos y su relación con la dinámica del arco y la formación de cuencas’, cuyo director es el Dr. A. Folguera (2010-2012 UBACyT). Asimismo es la contribución R-47 del Instituto de Estudios Andinos Don P. Groeber. Los autores desean agradecer la revisión crítica de los árbitros R. Giacosa, P. Duhart y M. Márquez por sus valiosas sugerencias, que mejoraron notablemente el manuscrito original, así como la labor del editor de la revista Dr. M. Suárez.

\section{Referencias}

Adriasola, A.C.; Thomson, S.N.; Brix, M.R.; Hervé, F.; Stockhert, B. 2006. Postmagmatic cooling and late Cenozoic denudation of the North Patagonian Batholith in the Los Lagos region of Chile, $41^{\circ}-42^{\circ} 15^{\prime}$ S. International Journal of Earth Science 95: 504-528.

Aragón, A.; Castro, A.; Díaz-Alvarado, J.; Liu, D.Y. 2011. The North Patagonian Batholith at Paso Puyehue (Argentina-Chile). SHRIMP ages and compositional features. Journal of South American Earth Sciences. doi:10.1016/j.jsames.2011.02.005

Asensio, M.; Zavala, C.; Arcuri, M. 2005. Los sedimentos terciarios del río Foyel, provincia de Río Negro, Argentina. In Congreso Geológico Argentino, No. 16, Actas: 271-276. Buenos Aires.

Asensio, M.; Cornou, M.; Malumián, N.; Martínez, M.A.; Quattrocchio, M. 2010. Formación Río Foyel, Oligoceno de la cuenca de Nirihuau: la transgresión pacífica en la Cordillera Norpatagónica. Revista de la Asociación Geológica Argentina 66 (3): 399-405.

Barreda, V.; García, V.; Quattrocchio, M.;Volkheimer, W. 2003. Edad y paleoambiente de la Formación Río Foyel, Cuenca de Nirihuau, provincia de Río Negro, Argentina. Revista Española de Micropaleontología 35 (2): 229-239.

Bertels, A. 1980. Foraminíferos (protozoa) y ostrácodos (Arthropoda) de las “Lutitas del Río Foyel” (Oligoceno) de la cuenca de Nirihuau, provincia de Río Negro, Argentina. Ameghiniana 17 (1): 49-52.

Busteros, A.; Franchi, M.; Lema, H. 1993. El magmatismo calcoalcalino del área de José de San Martín, provincia del Chubut. In Congreso Geológico Argentino, No. 12, Actas 4: 128-133. Mendoza.
Castro, A.; Moreno-Ventas, I.; Fernández, C.; Vujovich, G.; Gallastegui, G.; Heredia, N.; Martino, R.D.; Becchio, R.; Corretgé, L.G.; Díaz-Alvarado, J.; Such, P.; García-Arias, M.; Liu, D.Y. 2011. Petrology and SHRIMP U-Pb zircon geochronology of Cordilleran granitoids of the Bariloche area, Argentina. Journal of South American Earth Sciences (2011). doi:10.1016/j.jsames.2011.03.011

Cazau, L. 1972. Cuenca de Ñirihuau-Ñorquinco-Cushamen. In Geología Regional Argentina (Leanza, A.; editor). Academia Nacional de Ciencias: 727-740. Córdoba.

Cazau, L.; Mancini, D.; Cangini, J.; Spalletti, L. 1989. Cuenca de Nirihuau. In Cuencas Sedimentarias Argentinas (Chebli, G.; Spalletti, L.; editores). Serie Correlación Geológica 6: 299-318. Tucumán.

Charrier, R.; Pinto, L.; Rodríguez, M.P. 2007. Tectonostratigraphic evolution of the Andean Orogen in Chile. In The Geology of Chile (Moreno, T.; Gibbons, W.; editors). The Geological Society: 21-114. London.

Chiesa, J.O.; Camacho, H.H. 2001. Invertebrados marinos eocenos de la parte inferior de la Formación Río Foyel, provincia de Río Negro, Argentina. Revista Española de Paleontología 16 (2): 299-316.

Cingolani, C.; Hervé, F.; Munizaga, F.; Pankhurst, R.J.; Parada, M.A.; Rapela, C. 1991. The magmatic evolution of Northern Patagonia: New impressions of pre-Andean and Andean Tectonics. Geological Society of America Special Paper 265: 29-44.

Cornejo, P.; Matthews, S.; Pérez, C. 2003. The "K-T" compressive deformation event in northern Chile (24ํ-27ㅇ). In Congreso Geológico Chileno, No. 10, Actas, CD Rom. Concepción.

Dalla Salda, L.; Cingolani, C.; Varela, R. 1991. El basamento cristalino de la región nordpatagónica de los lagos Gutiérrez, Mascardi y Guillelmo, Provincia de Río Negro. Revista de la Asociación Geológica Argentina 46 (3-4): 263-276.

Diez, O.; Zubia, M. 1981. Sinopsis estratigráfica de la región de El Bolsón, provincia de Río Negro. Revista de la Asociación Geológica Argentina 36 (1): 19-28.

Duhart, P.; Crignola, G.; Ordóñez, B.A.; Muñoz, J. 2000. Franjas metalogénicas en Chiloé continental (41ㄷ $\left.44^{\circ} \mathrm{S}\right)$. In Congreso Geológico Chileno, No. 9, Actas: 201-205. Puerto Varas.

Egan, S.S.; Buddin, T.S.; Kane, S.J.; Williams, G.D. 1997. Three-dimensional modelling and visualisation in structural geology: New techniques for the restoration and balancing of volumes. In Proceedings of the 1996 Geoscience Information Group Conference on 
Geological Visualisation, Electronic Geology, No. 1, Paper 7: 67-82.

Encinas, A.; Pérez, F.; Orts, D.; Folguera, A.; Zurlo, D.; Ramos, V.A. 2010. Primeras dataciones U-Pb (LAICPMS) en zircones detríticos de las formaciones Río Foyel y La Cascada, Patagonia argentino-chilena, $41^{\circ}-43^{\circ}$ S. In Congreso Geológico Argentino, No. 18, Actas electrónicas. Neuquén.

Epard, J.L.; Groshong Jr.; R.H. 1993. Excess area and deph to detachment. American Association of Petroleum Geologists Bulletin 77 (8): 1291-1302.

Feruglio, E. 1927. Estudio geológico de la región pre y subandina en la latitud de Nahuel Huapi. Boletín de Informaciones Petroleras 4: 111-119.

Gabaldón, V.; Lizuaín, A. 1982. Estratigrafía y sedimentología del Liásico del noroeste del Chubut, Argentina. In Congreso Latinoamericano de Geología, No. 5, Actas 2: 509-526. Buenos Aires.

García-Sansegundo, J.; Farias, P.; Gallastegui, G.; Giacosa, R.E.; Heredia, N. 2009. Structure of the Gondwanan basement in the Bariloche region (North Patagonian Argentine Andes). International Journal of Earth Sciences 98: 1599-1608.

Giacosa, R.E.; Heredia, N.C. 1999. La cuenca de antepaís terciaria asociada a la faja plegada y corrida de los Andes Patagónicos entre los $41^{\circ}$ y los $42^{\circ} \mathrm{S}$, SO de Argentina. In Geología de los Andes Centrales Argentino-Chilenos (Busquets, P.; Colombo, F.; PérezEstaún, A.; Rodríguez Fernández, R.; editors). Acta Geológica Hispánica 32 (1-2): 103-111.

Giacosa, R.E.; Heredia, N.C. 2000. Estructura de los Andes Nordpatagónicos entre los $41^{\circ}$ y los $42^{\circ} \mathrm{S}$, Río Negro y Neuquén, Argentina. In Congreso Geológico Chileno, No. 9, Actas 2: 97-100. Puerto Varas.

Giacosa, R.; Heredia, N.; Césari, O.; Zubia, M.; González, R.; Faroux, A. 2001. Descripción geológica de la Hoja 4172-IV, San Carlos de Bariloche, Provincia de Río Negro (1:250.000). Servicio Geológico Nacional. Boletín 279: 1-77. Buenos Aires.

Giacosa, R.E.; Heredia, N.C. 2004. Estructura de los Andes Nordpatagónicos en los cordones Piltriquitrón y Serrucho y en el valle de El Bolsón (4130’-42º $)$, Río Negro. Revista de la Asociación Geológica Argentina 59 (1): 91-102.

Glodny, J.; Grâfe, K.; Echtler, H.; Rosenau, M. 2007. Mesozoic to Quaternary continental margin dynamics in South Central Chile ( $\left.36^{\circ}-42^{\circ} \mathrm{S}\right)$ : the apatite and zircon fission track perspective. International Journal of Earth Sciences 97: 1271-1291.
González Bonorino, F. 1973. Geología del área entre San Carlos de Bariloche y Llao-Llao. Fundación Bariloche, Publicación 16: 1-53. San Carlos de Bariloche.

González Bonorino, F. 1974. La Formación Millaqueo y la “Serie Porfirítica” de la Cordillera Nordpatagónica: nota preliminar. Revista de la Asociación Geológica Argentina 29 (2): 145-154.

González Bonorino, F.; González Bonorino, G. 1978. Geología de la región de San Carlos de Bariloche. Revista de la Asociación Geológica Argentina 33 (3): 175-210.

González Díaz, E.F. 1982. Chronological zonation of granitic plutonism in the Northern Patagonian Andes of Argentina: the migration of intrusive cicles. Earth Science Reviews 18: 365-393.

González Díaz, E.F.; Lizuaín, A. 1984. El Complejo Volcano-clástico y plutónico del sector cordillerano. In Geología y Recursos Naturales de la Provincia de Río Negro (Ramos, V.A.; editor), I (5): 119-138. San Carlos de Bariloche.

Gordon, A.; Ort, M. 1993. Edad y correlación del plutonismo subcordillerano en las provincias de Río Negro y Chubut. In Congreso Geológico Argentino, No. 12, Actas 4: 120-127. Mendoza.

Griffin, M.; Casadío, S.; Parras, A.; Feldmann, R.; Schweitzer, C. 2004. ${ }^{87} \mathrm{Sr} /{ }^{86} \mathrm{Sr}$ Early Oligocene age for the Río Foyel Formation, Río Negro, Argentina. Ameghiniana 41 (4), Suplemento, Resúmenes: 13.

Haller, M.; Linares, M.; Ostera, H.A.; Page, S. 1999. Petrology and geochronology of the Subcordilleran Plutonic Belt of Patagonia, Argentina. In South American Symposium on Isotope Geology (Carlos Paz), No. 2, Actas: 210-214. Servicio Geológico Minero Argentino (SEGEMAR), Buenos Aires.

Hervé, F.; Pankhurst, R.J.; Fanning, C.M.; Calderon, M.; Yaxley, G.M. 2007. The South Patagonian batholith: 150 my of granite magmatism on a plate margin. Lithos 97: 373-394.

Kane, S.J.; Williams, G.D.; Buddin, T.S.; Egan, S.S.; Hodgetts, D. 1997. Flexural-slip based restoration in 3D, a new approach. In 1997 American Association of Petroleum Geologists (AAPG), Annual Convention Official Program A58. Dallas, Texas.

Lizuaín, A. 1980. Las formaciones suprapaleozoicas y jurásicas de la Cordillera Patagónica, provincias de Río Negro y Chubut. Revista de la Asociación Geológica Argentina 35 (2): 174-182.

Lizuaín, A. 1981. Características y edad del plutonismo en los alrededores de Lago Puelo, Cordillera Patagó- 
nica (provincia de Chubut). In Congreso Geológico Argentino, No. 7, Actas 3: 607-616. Buenos Aires.

Lizuain, A. 1999. Estratigrafía y evolución geológica del Jurásico y Cretácico de la Cordillera Patagónica septentrional. In Geología Argentina (Caminos, R.; editor). Subsecretaría de Minería de la Nación, Servicio Geológico Minero Argentino, Instituto de Geología y Recursos Minerales, Anales 29: 433-556. Buenos Aires.

Ljungner, E. 1931. Geologische Aufnahmen in der Patagonischen Kordillera, Vorläufige Mitteilungen über statliche Arbeiten am See Nahuel Huapi in dem argentinischen National Park unter dem 41 Breitegrad. Bulletin of the Geological institution of the University of Upsala 23: 203-242.

McClay, K. 1999. Glossary of thrust tectonics terms. In Thrust Tectonics (McClay, K.; editor). Chapman \& Hall: 419-434. Londres.

Muñoz, J.; Troncoso, R.; Duhart, P.; Crignola, P.; Farmer, L.; Stern, C. 2000. The relationship of the mid-Tertiary coastal magmatic belt in south-central Chile to the late Oligocene increase in plate convergence rate. Revista Geológica de Chile 27 (2): 177-203.

Pankhurst, R.J.; Hervé, F.; Rojas, L.; Cembrano, J. 1992. Magmatism and tectonics in continental Chiloé (420 42³0’S). Tectonophysics 205: 283-294.

Pankhurst, R.J.; Hervé, F. 1994. Granitoid age distribution and emplacement control in the North Patagonian bathilith in Aysen ( $\left.44^{\circ}-47^{\circ} \mathrm{S}\right)$. In Congreso Geológico Chileno, No, 7, Actas 2: 1409-1413. Concepción.

Pankhurst, R.J.; Weaver, S.W.; Hervé, F.; Larrondo, P. 1999. Mesozoic-Cenozoic evolution of the North Patagonian Batholith in Aysén, southern Chile. Journal of the Geological Society 156: 673-694.

Pankhurst, R.J.; Rapela, C.W.; Fanning, C.M.; Márquez, M. 2006. Gondwanide continental collision and the origin of Patagonia. Earth-Science Reviews 76 (3): 235-257.

Pöthe de Baldis, D. 1984. Microfloras fósiles cenozoicas. In Geología y Recursos Naturales de la Provincia de Río Negro (Ramos, V.A.; editor), II (4): 393-412. Buenos Aires.

Quensel, P. 1911. Geologisch-petrographische Studien in der Patagonischen Cordillera. Bulletin of the Geological institution of the University of Upsala 11: 1-114.

Ramos, V.A. 1982. Las ingresiones pacíficas del Terciario en el norte de la Patagonia (Argentina). In Congreso Geológico Chileno, No. 3, I: A262-A268. Concepción.

Ramos, V.A.; Cortés, J. 1984. Estructura e interpretación tectónica. In Geología y Recursos Naturales de la Provincia de Río Negro (Ramos, V.A.; editor), I (12): 317-346. Buenos Aires.
Rapela, C.W.; Kay, S.M. 1988. Late Paleozoic to recent magmatic evolution of Northern Patagonia. Episodes 11 (3): 176-182.

Rapela, C.; Spaletti, L. Merodio, J. 1983. Evolución magmática y geotectónica de la “Serie Andesítica” andina (PaleocenoEoceno) en la Cordillera Nordpatagónica. Revista de la Asociación Geológica Argentina 38 (3-4): 469-484.

Rapela, C.; Munizaga, F.; Dalla Salda, L.; Hervé, F.; Parada, M.; Cingolani, C. 1987. Nuevas edades K-Ar de los granitoides del sector nororiental de los Andes Patagónicos. In Congreso Geológico Argentino, No. 10, Actas 4: 18-20. Tucumán.

Rapela, C.; Spaletti, L.; Merodio, J.; Aragón, E. 1988. Temporal evolution and spatial variation of early Tertiary

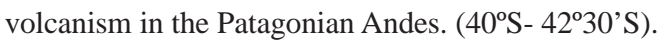
Journal of South American Earth Sciences 1 (1): 75-88.

Rapela, C.; Pankhurst, R.J.; Fanning, C.M.; Hervé, F. 2005. Pacific subduction coeval with the Karoo mantle plume: the Early Jurassic Subcordilleran belt of northwestern Patagonia. In Terrain processes at the margins of Gondwana (Vaugham, A.P.M.; Leat, P.T.; Pankhurst, R.J.; editors). Geological Society of London, Special Publications 246: 217-239.

Rodgers, J. 1971. The Taconic orogeny. Geological Society of America Bulletin 82: 1141-1178.

Spalletti, L.A. 1983. Paleogeografía de la Formación Ñirihuau y sus equivalentes en la región occidental de Neuquén, Río Negro y Chubut. Revista de la Asociación Geológica Argentina 38 (3-4): 454-468.

Spalletti, L.A.; Matheos, S.D. 1987. Composición de sedimentitas silicoclásticas terciarias de la cuenca de Ñirihuau (Patagonia Occidental) y su significado tectónico. Revista de la Asociación Geológica Argentina 42 (3-4): 322-337.

Spikermann, J.P.; Strelin, J.A.; Marshall, P.; Carrillo, R.; Montenegro, T.; Lago, M.; Villalba, E.; Pérez, A. 1988. Geología del area El Batolito Aleusco, Departamento de Languineo, provincia de Chubut. Revista de la Asociación Argentina de Mineralogía, Petrología y Sedimentología 19 (1): 39-48.

Spikermann, J.P.; Strelin, I.; Marshall, P.; Carrillo, R.; Montenegro, T.; Lago, M.; Villalba, E.; Pérez, A. 1989. Caracterizacion geológica y petrológica del Batolito Aleusco, Departamento de Languineo, provincia de Chubut. Revista de la Asociación Argentina de Mineralogía, Petrología y Sedimentología 20 (1): 33-42.

Suárez, M.; Márquez, M. 2007. A toarcian back-arc basin of central patagonia (Chubut), Argentina: middle jurassic closure and tectonic setting. Revista Geológica de Chile 34 (1): 63-79. 
Suárez, M.; De la Cruz, R. 2000. Tectonics in the eastern central Patagonian Cordillera (4530'-4730'S). Journal of the Geological Society 157: 995-1001.

Suppe, J. 1983. Geometry and Kinematics of fault-bend folding. American Journal of Sciences 283: 684-721.

Thiele, R.; Castillo, J.C.; Hein, R.; Romero, G.; Ulloa, M. 1978. Geología del sector fronterizo de Chiloé continental entre los $43^{\circ} 43^{\circ} 45^{\prime}$ latitud sur, Chile (columnas de Futaleufú y Palena). In Congreso Geológico Argentino, No. 7, Actas I: 577-591. Neuquén.

Thomson, S.N. 2002. Late Cenozoic geomorphic and tectonic evolution of the Patagonian Andes between latitudes $42^{\circ}$ and $46^{\circ} \mathrm{S}$ : An appraisal based on fissiontrack results from the transpressional intra-arc LiquiñeOfqui fault zone. Geological Society of America Bulletin 114: 1159-1173.

Thomson, S.N.; Hervé, F.; Stökhert, B. 2001. MesozoicCenozoic denudation history of the Patagonian Andes (southern Chile) and its correlation to different subduction processes. Tectonics 20 (5): 693-711.
Tobal, J. 2010. Estudio geológico del cordón del Hielo Azul al oeste de El Bolsón (Pcia. de Río Negro). Tesis final de licenciatura (Inédita), Universidad de Buenos Aires: 88 p.

Tunik, M.; Folguera, A.; Naipauer, M.; Pimentel, M.; Ramos, V.A. 2010. Early uplift and orogenic deformation in the Neuquén basin: constraints on the Andean uplift from $\mathrm{U} / \mathrm{Pb}$ and $\mathrm{Hf}$ analyses of detrital zircons. Tectonophysics 489: 258-273.

Turner, J.C. 1965. Estratigrafía de Aluminé y adyacencias, provincia de Neuquén. Revista de la Asociación Geológica Argentina 20 (2): 153-184.

Varela, R, Basei, M.; Cingolani, C.; Siga Jr., O.; Passarelli, C. 2005. El basamento cristalino de los Andes norpatagónicos en Argentina: geocronología e interpretación tectónica. Revista Geológica de Chile 32 (2): 167-187.

Zamora Valcarce, G.; Zapata, T.; Ramos, V.; Rodríguez, F.; Bernardo, L. 2009. Evolución tectónica del Frente Andino en Neuquén. Revista de la Asociación Geológica Argentina 65 (1): 192-203.

Manuscript received: May 24, 2011; revised/accepted: September 20, 2011; available online: June 19, 2012. 